\title{
Evaluation of the Hydrological Cycle in the ECHAM5 Model
}

\author{
Stefan Hagemann, Klaus Arpe, and Erich Roeckner \\ Max Planck Institute for Meteorology, Hamburg, Germany
}

(Manuscript received 24 January 2005, in final form 18 August 2005)

\begin{abstract}
This study investigates the impact of model resolution on the hydrological cycle in a suite of model simulations using a new version of the Max Planck Institute for Meteorology atmospheric general circulation model (AGCM). Special attention is paid to the evaluation of precipitation on the regional scale by comparing model simulations with observational data in a number of catchments representing the major river systems on the earth in different climate zones. It is found that an increased vertical resolution, from 19 to 31 atmospheric layers, has a beneficial effect on simulated precipitation with respect to both the annual mean and the annual cycle. On the other hand, the influence of increased horizontal resolution, from T63 to T106, is comparatively small. Most of the improvements at higher vertical resolution, on the scale of a catchment, are due to large-scale moisture transport, whereas the impact of local water recycling through evapotranspiration is somewhat smaller. At high horizontal and vertical resolution (T106L31) the model captures most features of the observed hydrological cycle over land, and also the local and remote precipitation response to El Niño-Southern Oscillation (ENSO) events.

Major deficiencies are the overestimation of precipitation over the oceans, especially at higher vertical resolution, along steep mountain slopes and during the Asian summer monsoon season, whereas a dry bias exists over Australia. In addition, the model fails to reproduce the observed precipitation response to ENSO variability in the Indian Ocean and Africa. This might be related to missing coupled air-sea feedbacks in an AGCM forced with observed sea surface temperatures.
\end{abstract}

\section{Introduction}

The hydrological cycle is crucially important to life on earth. An accurate representation of the exchanges of water between the atmosphere, the ocean, the cryosphere, and the land surface is one of the biggest challenges in global climate modeling. Simulating these fluxes is extremely difficult, because they depend on processes that are generally several orders of magnitude smaller than the typical grid size in a general circulation model (GCM). The formation of precipitation, for example, is controlled by a multitude of processes such as cloud microphysics and particle growth, radiative transfer, atmospheric dynamics on a variety of space and time scales, and inhomogeneities of the earth's surface, all of which have to be properly represented in a GCM. On the other hand, the general circulation of the atmosphere is driven largely by the re-

Corresponding author address: Dr. Stefan Hagemann, Max Planck Institute for Meteorology, Bundesstrasse 53, 20146 Hamburg, Germany.

E-mail: stefan.hagemann@zmaw.de lease of latent heat due to rain and snow formation. At longer time scales, the hydrological cycle affects the groundwater storage, the thermohaline circulation in the ocean, and the evolution of glaciers and ice sheets.

The focus of this study is on the comparison of simulated and observed climatologies of precipitation, evaporation, and river runoff. Unfortunately, this comparison is hampered by the lack of good-quality datasets on the global scale. Gridded precipitation climatologies are somewhat similar over land but differ considerably over the ocean where rain gauge measurements hardly exist. Therefore, we place our emphasis on land surfaces. In particular, we assess the resolution dependence of the water fluxes at the earth's surface as derived from a series of Atmospheric Model Intercomparison Project (AMIP)-style experiments using a new version (cycle 5) of the ECHAM model. The analysis of other components of the hydrological cycle like clouds, snow, or soil moisture is beyond the scope of this study. A detailed evaluation of the simulated snow climatology and variability in ECHAM5 can be found in Roesch and Roeckner (2006).

The model and the simulations considered in this 
study are briefly described in section 2. Simulated and observed components of the hydrological cycle are compared in section 3 . The precipitation response to observed warm and cold episodes in the equatorial East Pacific is discussed in section 4, and the main findings are summarized in section 5 .

\section{Model description, model simulations, and observational data}

A comprehensive model description of ECHAM5 and its climatology can be found in Roeckner et al. (2003, 2006). Its main components relevant for the simulation of the hydrological cycle are summarized as follows. The model employs a spectral dynamical core. Vorticity, divergence, temperature, and the logarithm of surface pressure are represented in the horizontal by a truncated series of spherical harmonics. Triangular truncation is used at wavenumbers $21,31,42,63,85$, 106 , or 159. A hybrid coordinate system is used in the vertical direction: the sigma system at the lowest model level gradually transforms into a pressure system in the lower stratosphere. In the standard configuration, the uppermost computational level is at $10 \mathrm{hPa}$ with a total of either 19 or 31 levels. A flux form semi-Lagrangian scheme (Lin and Rood 1996) is used for passive tracer transport, that is, for all water components (vapor, liquid, and solid) and for chemical substances (optional).

The shortwave radiation scheme (Fouquart and Bonnel 1980) uses the Eddington approximation for the integration over the zenith and azimuth angles and the delta-Eddington approximation for the reflectivity of a layer. The scheme has four spectral bands, one for the visible + UV range, and three for the near infrared. In the longwave, the so-called Rapid Radiative Transfer Model (RRTM) based on the correlated- $k$ method (Mlawer et al. 1997) is used. The computation is organized in 16 spectral bands and includes line absorption by $\mathrm{H}_{2} \mathrm{O}, \mathrm{CO}_{2}, \mathrm{O}_{3}, \mathrm{CH}_{4}, \mathrm{~N}_{2} \mathrm{O}, \mathrm{CFC}-11, \mathrm{CFC}-12$, and aerosols.

The stratiform cloud scheme consists of prognostic equations for the water phases (vapor, liquid, and solid), bulk cloud microphysics (Lohmann and Roeckner 1996), and a statistical cloud cover scheme with prognostic equations for the distribution moments (Tompkins 2002). The microphysics scheme includes phase changes between the water components (condensation/evaporation, deposition/sublimation, and freezing/melting) and precipitation processes (autoconversion, accretion, and aggregation). Moreover, the evaporation of rain and the melting of snow are considered as well as the sedimentation of cloud ice.

For cumulus convection, a mass flux scheme is em- ployed (Tiedtke 1989) with modifications for deep convection according to Nordeng (1994). Cloud water detrainment in the upper part of convective updrafts is used as a source term in the stratiform cloud water equations. For deep convection, an adjustment-type closure is used with convective activity being expressed in terms of convective available potential energy (CAPE).

The turbulent surface fluxes for momentum, heat, and moisture are obtained from bulk transfer relationships involving the difference of the respective model variable between the surface and the lowest model level, the wind velocity at that level, and the transfer coefficients. The latter are obtained from the MoninObukhov similarity theory by integrating the flux profile relationships between the surface and the lowest model level. Over land, the roughness length is a function of subgrid-scale orography and vegetation. Over the sea, the aerodynamic roughness depends on friction velocity, whereas the roughness length for heat transfer has to be adjusted owing to the fact that the transfer coefficient is largely independent of wind speed. In unstable conditions, an interpolation is used between the free convection limit and the neutral approximation. Over land, transpiration is limited by the stomatal resistance, and bare soil evaporation is limited by the availability of soil water.

The land surface temperature is obtained from the surface energy balance equation using an implicit coupling scheme that is unconditionally stable and allows us to synchronously calculate the respective prognostic variables and surface fluxes. The surface temperature is used as a boundary condition to determine the vertical profile within the five-layer soil model assuming vanishing heat fluxes at the bottom (10-m depth). Four reservoirs are defined for the water components: snow at the canopy, snow at the surface, liquid water at the canopy, and soil water. The dataset of land surface parameters utilized in ECHAM5 has been compiled by Hagemann (2002a) from a global distribution of major ecosystem types that was made available by the U.S. Geological Survey.

A series of AMIP-style experiments (Gates et al. 1999) was performed using observed monthly sea surface temperatures (SSTs) and sea ice cover for the time period 1978-99. The output of the first year of each experiment was omitted. Except for model tuning (see below), the experiments differ only with respect to horizontal resolution (T21, T31, T42, T63, T85, T106, and T159; corresponding to grid sizes at the equator of about $625,417,313,208,156,125$, and $83 \mathrm{~km}$, respectively) and vertical resolution (L19 and L31). The impact of these resolution changes on simulated tropo- 
TABLE 1. Resolution dependence of model-simulated global annual mean precipitation (1979-99). Units are $\mathrm{mm}^{\text {day }}{ }^{-1}$ for total, convective, and large-scale precipitation; and percent for the ratio of convective and total precipitation.

\begin{tabular}{|c|c|c|c|c|c|c|c|c|}
\hline \multirow[b]{2}{*}{ Resol. } & \multicolumn{4}{|c|}{ L19 } & \multicolumn{4}{|c|}{ L31 } \\
\hline & $P_{\text {total }}$ & $P_{\text {conv }}$ & $P_{1 . \mathrm{s} .}$ & $P_{\text {conv }} / P_{\text {total }}$ & $P_{\text {total }}$ & $P_{\text {conv }}$ & $P_{1 . \mathrm{s} .}$ & $P_{\text {conv }} / P_{\text {total }}$ \\
\hline $\mathrm{T} 21$ & 2.821 & 1.837 & 0.983 & 65.1 & - & - & - & - \\
\hline T31 & 2.840 & 1.757 & 1.083 & 61.9 & - & - & - & - \\
\hline $\mathrm{T} 42$ & 2.886 & 1.749 & 1.137 & 60.6 & 2.964 & 1.711 & 1.253 & 57.7 \\
\hline T63 & 2.916 & 1.703 & 1.213 & 58.4 & 2.990 & 1.553 & 1.438 & 51.9 \\
\hline $\mathrm{T} 85$ & 2.920 & 1.665 & 1.255 & 57.0 & 3.008 & 1.528 & 1.479 & 50.8 \\
\hline T106 & 2.924 & 1.653 & 1.271 & 56.5 & 3.031 & 1.533 & 1.498 & 50.6 \\
\hline T159 & - & - & - & - & 3.079 & 1.486 & 1.593 & 48.3 \\
\hline
\end{tabular}

spheric climate has been discussed by Roeckner et al. (2006). In our study, the emphasis will be mainly on the simulations with higher horizontal resolution (T63 and T106). In all experiments the top level is placed at 10 $\mathrm{hPa}$. The top three and the bottom three levels are identical in both grids. In the L19 (L31) model configuration the geometrical grid spacing in the free troposphere increases gradually with height from about $1 \mathrm{~km}$ $(500 \mathrm{~m})$ in the lower troposphere, to $1.5 \mathrm{~km}(750 \mathrm{~m})$ in the middle troposphere, and $2 \mathrm{~km}(1 \mathrm{~km})$ around the tropopause. The exact position of the model layers at both resolutions can be found in the model documentation (Roeckner et al. 2003, their Table 2.2). Except for a few parameter changes, the physical package remains identical. Some of the parameter changes are directly linked to resolution changes as, for instance, the damping time of the highest resolvable wavenumber in the horizontal diffusion scheme. Other parameters had to be tuned in order to approximately satisfy the long-term mean radiation balance at the top of the atmosphere (Roeckner et al. 2006).

Observational datasets used for model validation are the global precipitation climatologies, the Global Precipitation Climatology Project (GPCP; Huffman et al. 1997) and the Climate Prediction Center (CPC) Merged Analysis of Precipitation (CMAP; Xie and Arkin 1997). These estimates have large uncertainties over the ocean where precipitation is not directly measured but derived from radiances measured by satellites. Thus, the quality of these estimates largely depends on the model algorithms used to derive the precipitation amounts (Adler et al. 2001; Hagemann 2002b). For model validation, several catchments were selected, for which river discharge data have been compiled by Dümenil Gates et al. (2000). The catchments comprise the following regions representing different climate regimes: the Amazon, Amur, Arctic Ocean, represented by its six largest rivers (Jenisei, Kolyma, Lena, Mackenzie, Northern Dvina, and $\mathrm{Ob}$ ), Baltic Sea catchment (land only), Congo, Danube, Ganges/Brahmaputra, Mississippi, Murray, Nile, Parana, and Yangtze Kiang.

\section{Validation of the hydrological cycle}

\section{a. Global scale}

An overview of the resolution dependence of global annual mean precipitation is presented in Table 1. Note that convective precipitation is the fraction of total precipitation that is instantaneously released in convective updrafts, whereas the fraction generated through convective detrainment is defined as large scale. No distinction is made between stratiform clouds formed through supersaturation (mainly at middle and high latitudes) and those formed through convective detrainment (mainly at low latitudes). At both vertical resolutions, L19 and L31, total and large-scale precipitation increases monotonously with increasing horizontal resolution, whereas convective precipitation decreases. Similarly, an increasing vertical resolution results in a systematic increase of total and large-scale precipitation and in a decrease of convective precipitation. Total precipitation increases by about $9 \%$ between T21L19 and T159L31, whilst the ratio of convective and total precipitation decreases from $65 \%$ in T21L19 to less than 50\% in T159L31. As to be expected, the changes in global precipitation are closely related to changes in the atmospheric radiation budget. Little sensitivity to resolution is found for the solar atmospheric heating, for the longwave cloud radiative forcing of the atmosphere, and for the sensible heat flux. The largest sensitivity to resolution is found for the clear-sky longwave cooling of the atmosphere, which monotonously increases from $-176 \mathrm{~W} \mathrm{~m}^{-2}$ at T21L19 resolution to $-183 \mathrm{~W} \mathrm{~m}^{-2}$ at T159L31 resolution. This increase in atmospheric radiative cooling, which is closely related to the amount and spatial distribution of atmospheric water vapor (Roeckner et al. 2006), is sufficient to compensate for the increase in global precipitation shown in Table 1. These sensitivities to resolution are found essentially over the ocean, whereas the opposite is found over the land (see below), where the surface radiation has a larger control on convective cloud formation and precipitation, than over the ocean, 
where the heat budget is not closed because the SST is prescribed. In coupled atmosphere-ocean models the sensitivity to resolution could be smaller due to the close coupling between SST, convective cloud formation, and surface heat fluxes over the low-latitude oceans.

At middle and higher latitudes, the increase of largescale and total precipitation at higher resolution is governed essentially by enhanced near-surface winds, by stronger ascent at low latitudes, and compensating subsidence and drying in the subtropics (Roeckner et al. 2006). All of these processes contribute to the larger evaporation and precipitation over the global ocean. The decrease of convective precipitation in the L31 simulations is closely related to enhanced detrainment of convective cloud water in the tropical midtroposphere (Inness et al. 2001; Roeckner et al. 2006) causing an increase of large-scale precipitation in these regions at the expense of the convective component.

These results are qualitatively similar to those obtained by Pope and Stratton (2002) with an L30 version of the Third Hadley Centre Atmospheric Model (HadAM3) at horizontal resolutions ranging between $\mathrm{N} 48\left(2.5^{\circ} \times 3.75^{\circ}\right.$, corresponding to about $\left.\mathrm{T} 42\right)$ and $\mathrm{N} 144\left(0.833^{\circ} \times 1.25^{\circ}\right.$, corresponding to about T106). The main difference to ECHAM5 is that the convective component is substantially higher $(75.4 \%$ of total precipitation for $\mathrm{N} 48$ and $71.3 \%$ for N144) whereas the amount of total precipitation is similar and so is its change with increasing horizontal resolution.

Figure 1 shows a comparison of simulated and observed annual mean precipitation and evaporation integrated separately over (a) all land area and (b) all ocean area. Over the land, the sensitivity to horizontal resolution is relatively small, whereas both precipitation and evaporation are smaller in the L31 simulations, in reasonable agreement with the estimates of Baumgartner and Reichel (1975) for both precipitation and evaporation and GPCP for precipitation. CMAP precipitation data are not corrected for the systematic undercatch of precipitation gauges, which is especially significant for snowfall. For GPCP data, a correction has been applied by GPCP during the construction of their gridded dataset from gauge measurements. This correction is known to be overestimated by a factor of about 2 (Rudolf and Rubel 2005) so that the actual precipitation amounts are expected to be in between GPCP and CMAP.

Over the ocean, the simulated precipitation and evaporation are substantially larger than in all observational estimates, and the increase of both components with increasing horizontal and vertical resolution is significantly larger than over land. The effect of an in-

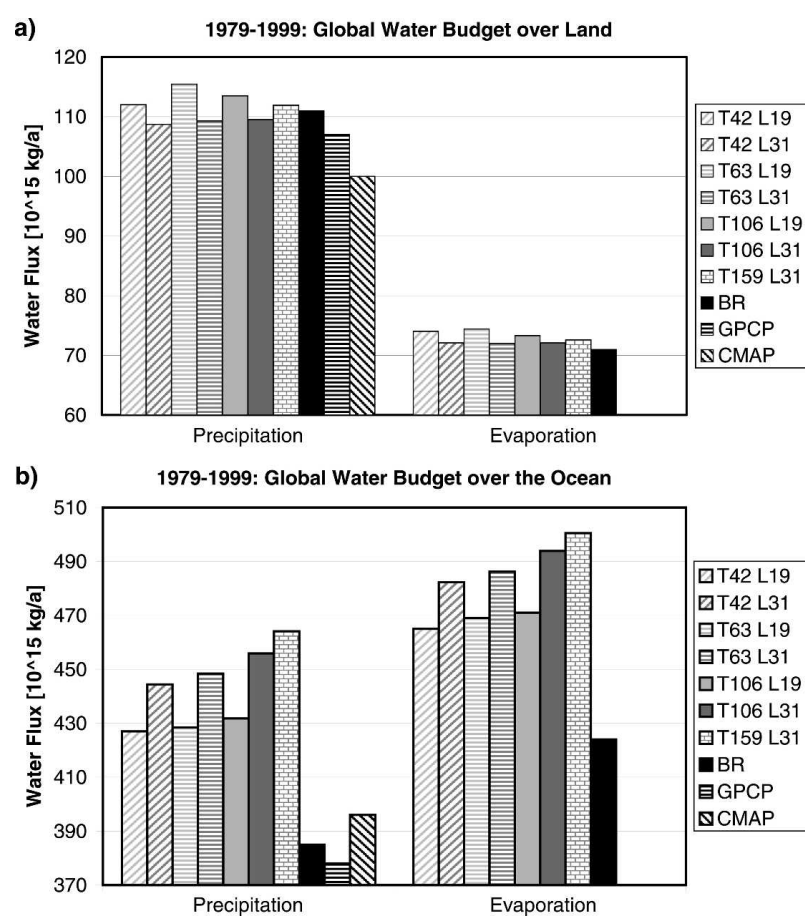

FIG. 1. Global water budget over (a) land and (b) ocean for the period 1979-99. The BR designates climatological estimates of Baumgartner and Reichel (1975). Unit: $10^{15} \mathrm{~kg} \mathrm{a}^{-1}$.

creased horizontal resolution is smaller compared to an increased vertical resolution. Probably for wrong reasons, the best agreement between simulation and observation is found for a low-resolution model configuration (T21L19; not shown). Better agreement with observations was obtained with ECHAM4 (Roeckner et al. 1996) where the hydrological cycle was weakened by the large absorption of solar radiation in clouds (18 W $\mathrm{m}^{-2}$ globally compared to $3 \mathrm{~W} \mathrm{~m}^{-2}$ in ECHAM5). Assuming that the changes in the other heat fluxes (longwave, sensible, and latent) are comparatively small, the decreased cloud absorption in ECHAM5 would correspond to an increase in global precipitation by about 0.5 mm day ${ }^{-1}$ compared to ECHAM4.

Although "anomalous cloud absorption" is still a matter of scientific debate (Valero et al. 2004; Li et al. 2004), the high cloud absorption in ECHAM4 was found to be a numerical artifact due to the insufficient spectral resolution (two bands) in the shortwave radiation code (Wild et al. 1998). By doubling the number of bands in ECHAM5 the spurious cloud absorption was removed, but the hydrological cycle became too intense. This is a general problem in current GCMs, which could possibly be related to inaccuracies of radiation codes like insufficient absorption by water vapor, aerosols, or clouds. 


\section{b. Zonal means}

Figure 2 shows the zonal distribution of simulated and observed precipitation over land for the boreal winter [December-January-February (DJF)] and the boreal summer [June-July-August (JJA)]. For the sake of clarity results are shown only for the T63 and T106 simulations. In all simulations the precipitation maximum around $10^{\circ} \mathrm{S}$ is too high. Also, the peaks at $50^{\circ}$ and $70^{\circ} \mathrm{S}$ (orographic precipitation at the coast of South America and Antarctica, respectively) are unrealistic, whereas the distribution in the Northern Hemisphere is well captured (slightly higher than CMAP but close to GPCP). In boreal summer the meridional distribution between about $40^{\circ} \mathrm{S}$ and $30^{\circ} \mathrm{N}$ is well simulated. Poleward of about $40^{\circ}$ the simulated precipitation is larger than observed, and there is an unrealistic peak at about $30^{\circ} \mathrm{N}$. The effect of both horizontal and vertical resolution on the latitudinal distribution of precipitation over land is relatively small. Also, the observational estimates are reasonably similar in most regions.

This changes over the ocean (Fig. 3) where GPCP provides considerably smaller values than CMAP in the Tropics but larger values in the extratropics. In DJF, the double peak in observed precipitation at $10^{\circ} \mathrm{N}$ and

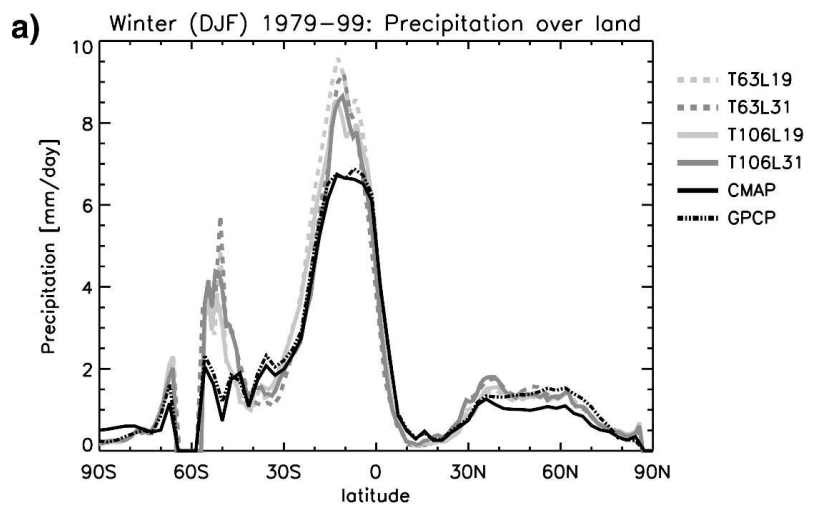

b) Summer (JJA) 1979-99: Precipitation over land

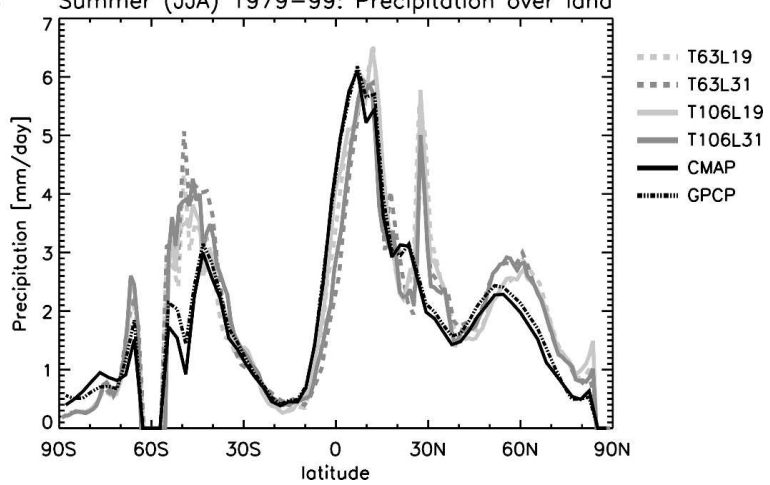

FIG. 2. Zonal distribution of precipitation over land in the boreal (a) winter and (b) summer. Unit: $\mathrm{mm} \mathrm{day}^{-1}$
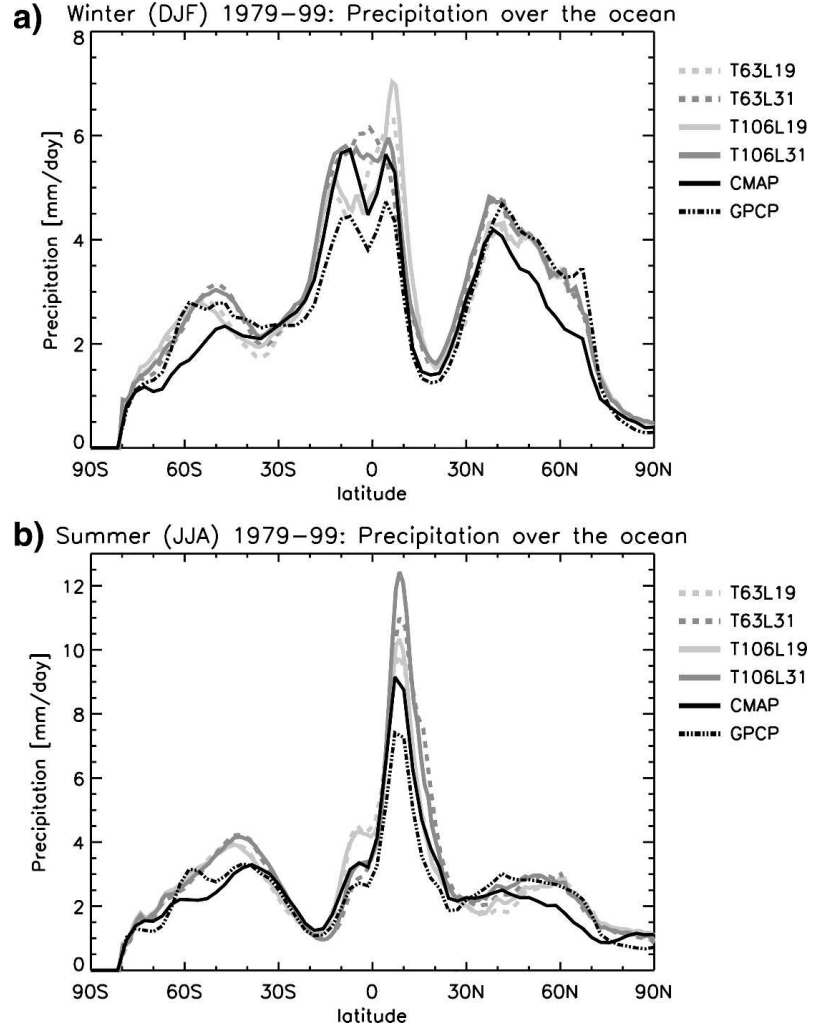

Fig. 3. Same as in Fig. 2, but for precipitation over the ocean.

$10^{\circ} \mathrm{S}$, respectively, is captured by none of the model configurations. The L19 model configurations simulate a single peak at about $10^{\circ} \mathrm{N}$, whereas the L31 model configurations produce a broad distribution. All model configurations overestimate precipitation at lower latitudes, in particular in comparison to GPCP. In the extratropics there is good agreement between model and GPCP, whereas the model estimates are higher than CMAP. Note that the CMAP climatology over extratropical oceans has been supplemented by National Centers for Environmental Prediction-National Center for Atmospheric Research (NCEP-NCAR) reanalysis data (Kalnay et al. 1996). In JJA (Fig. 3b), the tropical peak at about $10^{\circ} \mathrm{N}$ is well captured, but the simulated precipitation is enhanced compared to CMAP and GPCP, especially at higher horizontal and vertical resolution. Between $0^{\circ}$ and $10^{\circ} \mathrm{S}$ precipitation is overestimated in the L19 simulations but realistic in the L31 simulations. As in the boreal winter, the simulated precipitation in the extratropics is closer to GPCP than to CMAP.

\section{c. Geographic distributions}

Figure 4 shows a comparison of simulated (T106L31) and observed (CMAP) precipitation climatologies for 
T106L31

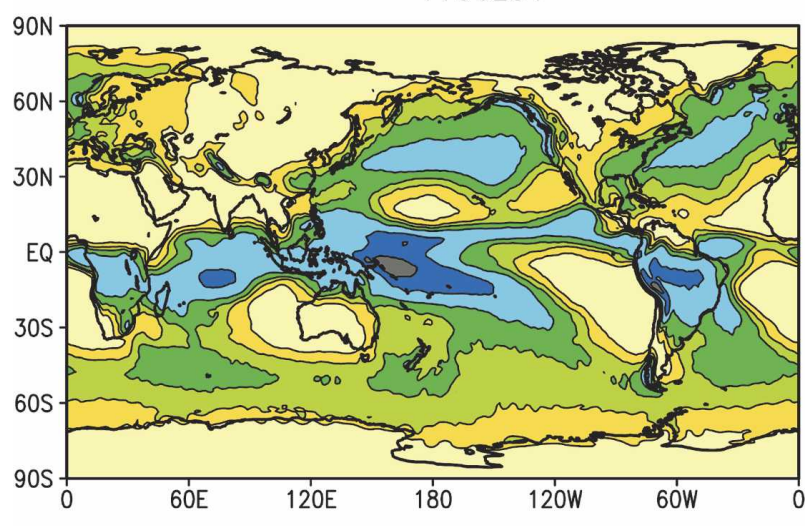

CMAP

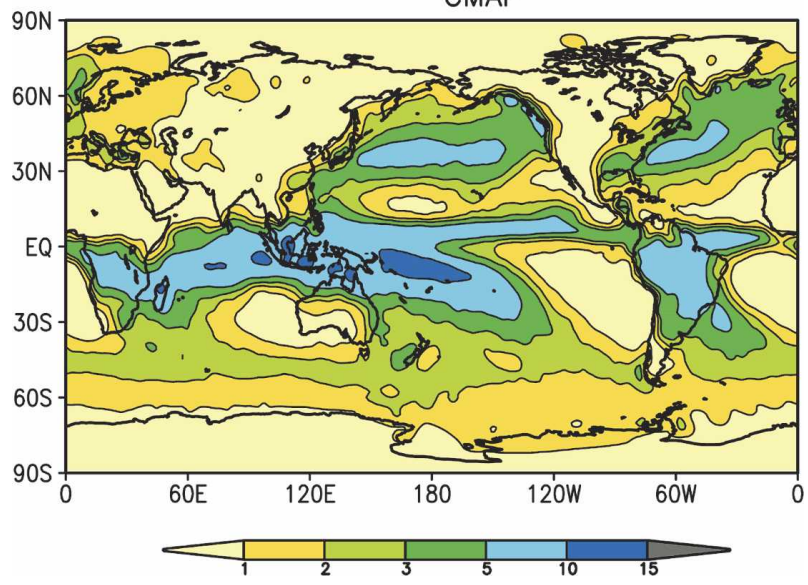

FIG. 4. Geographic distributions of simulated (T106L31) and observed (CMAP) precipitation in the boreal winter (DJF) for the time period 1979-98. Unit: $m$ day $^{-1}$.

the boreal winter. The large-scale pattern of precipitation like the distribution of "wet" regions $(P>5 \mathrm{~mm}$ day $\left.^{-1}\right)$ and "dry" regions $\left(P<1 \mathrm{~mm}\right.$ day $\left.^{-1}\right)$ is well captured in the simulation, but the maxima in the Tropics (Brazil and west Pacific warm pool) and within the extratropical storm tracks are too pronounced. However, as noted earlier, the uncertainties of observed climatologies over the oceans are relatively large. Spuriously high precipitation can also be found along steep mountain slopes (Andes, Himalayas, and Rocky Mountains). Precipitation is also too high over Europe and in a region stretching from the southwestern United States to the west coast of Central America. There are only few regions where precipitation is underestimated (Australia and north coast of South America). Analogous to DJF, the broad pattern of precipitation is well captured also in boreal summer (Fig. 5), but the maxima over the oceans are too intense (west Pacific warm pool, intertropical convergence zone, Bay of Bengal, and extratropical storm tracks), and precipita-
T106L31
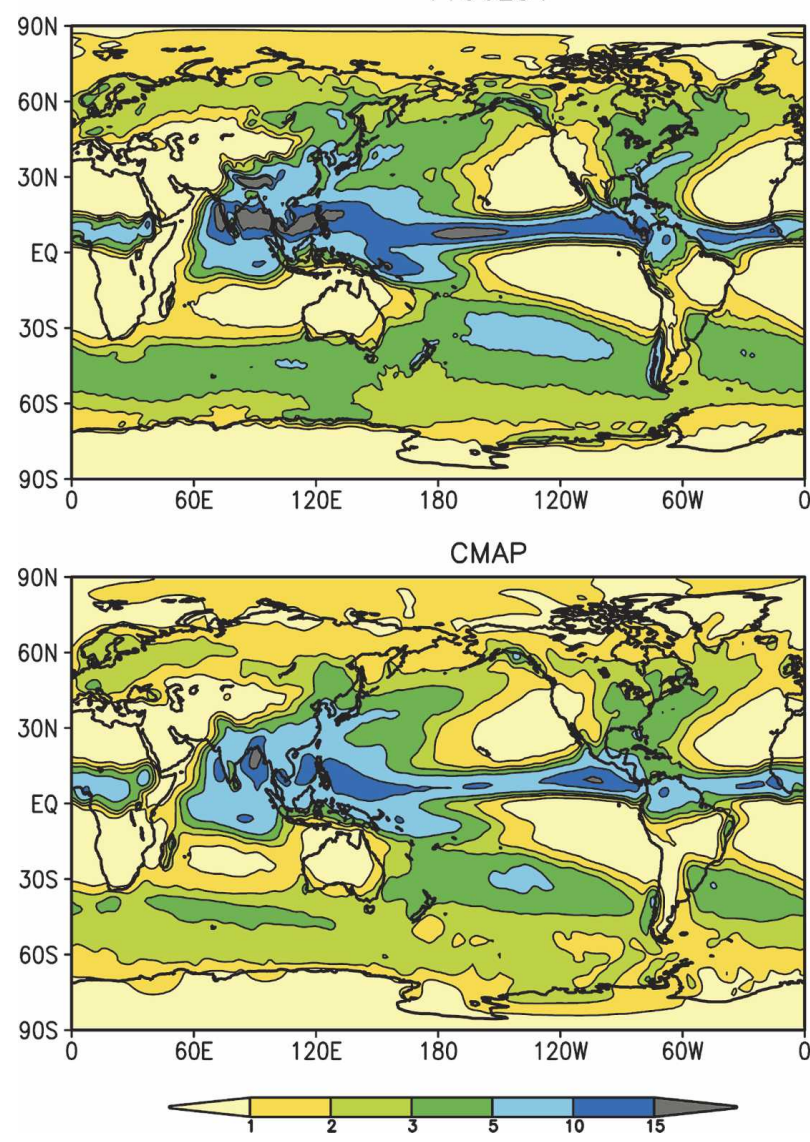

FIG. 5. Same as in Fig. 4, but in the boreal summer (JJA).

tion is also spuriously high along steep mountain slopes (Andes, Himalayas, and western Ghats). Over land, the errors are considerably smaller. Precipitation is somewhat high (also compared to GPCP; see Fig. 2b) at high northern latitudes (Canada and Siberia). The tropical maxima over Africa and South America are well represented except that the rainfall over Africa is slightly underestimated south of the equator.

\section{d. Integrated water vapor}

Figure 6 shows the zonal means of integrated water vapor (IWV) from the T63 and T106 simulations for the period 1988-99. This period was chosen as it overlaps with the availability of the water vapor analysis of the National Aeronautics and Space Administration (NASA) Water Vapor Project (NVAP; Randel et al. 1996). In addition, IWV estimates of the 40-yr European Centre for Medium-Range Weather Forecasts (ECMWF) Re-Analysis (ERA-40; Uppala et al. 2005) are used for comparison. The ECHAM5 IWV agrees well with the observational estimates over land except 
a)

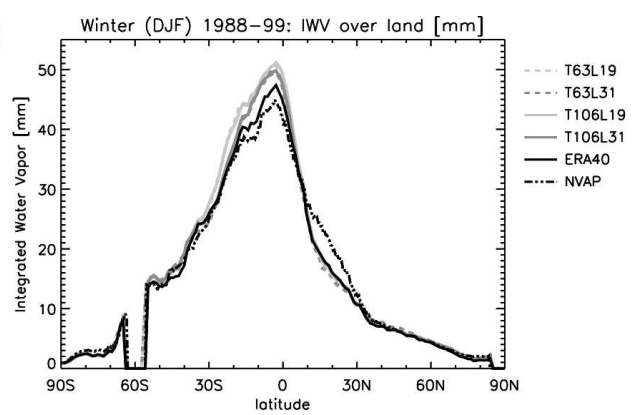

c)

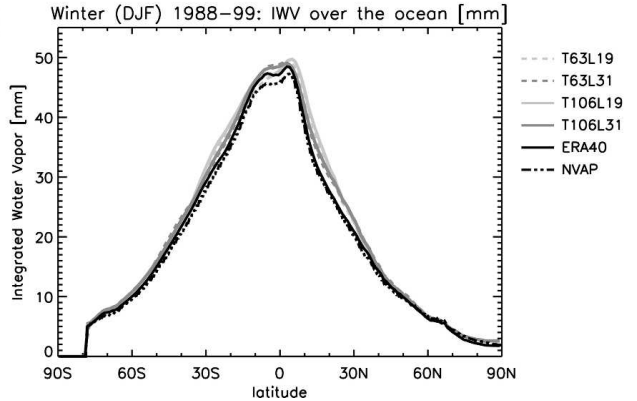

b)

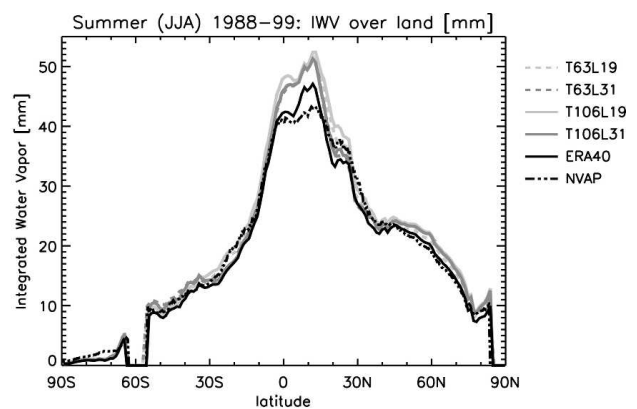

d)

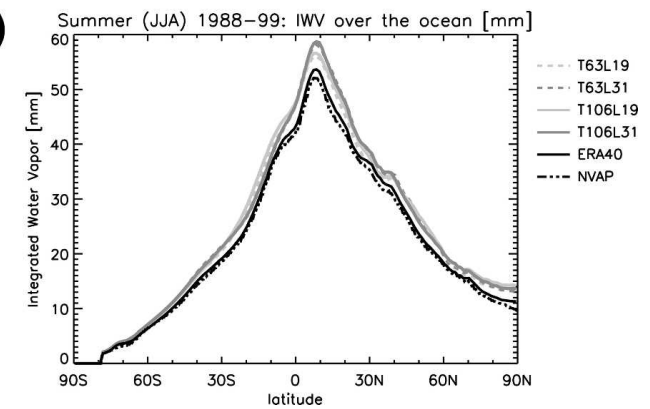

FIG. 6. Zonal distribution of IWV over land in the boreal (a) winter and (b) summer, and over the ocean in the boreal (c) winter and (d) summer. Unit: $\mathrm{mm}$.

for the Tropics where IWV is overestimated (Figs. $6 a, b)$. In the boreal winter, the NVAP IWV data seem to have a problem over the northern low latitudes where they significantly differ from the ERA-40 data and the ECHAM5 simulations. This difference is caused by relatively wet NVAP values over the Sahara and the Sahel zone that are probably too large (not shown). Over the ocean there is a general overestimation of IWV by ECHAM5, which is more pronounced in the boreal summer (Fig. 6d) than in the boreal winter (Fig. 6c). The influence of different resolutions on the zonal mean IWV is comparatively small. At lower latitudes, the simulated IWV is somewhat smaller in the L31 simulations than in the L19 simulations, except over the ocean around the equator in the corresponding summer hemisphere (south of the equator in DJF; north of the equator in JJA).

Figure 7 shows the geographical distribution of IWV for the boreal summer (JJA) 1988-99. Here, only T106L31 data are compared to the observational estimates, as the simulated IWV distribution does not differ significantly between the different model configurations. Generally the geographical distribution of simulated IWV agrees quite well with both observational estimates. Larger positive deviations are found in the tropical belt near the equator, especially in the tropical Pacific. The overestimation of IWV over the ocean is related to a warm bias in the tropospheric temperatures, which are warmer than observed by $1-2 \mathrm{~K}$ in boreal summer (Roeckner et al. 2006). In boreal winter, no tropospheric warm bias can be seen. Here, the simulated IWV is only slightly overestimated in the tropical Pacific and over the Amazonian rainforest (not shown).

\section{e. Hydrological cycle and temperature in river catchments}

The distribution of catchments selected for the model validation is shown in Fig. 8. The largest rivers on earth are included as well as a few smaller ones in Europe (Baltic Sea and Danube) and Australia (Murray). Biases of annual mean precipitation $(P)$, evaporation $(E)$, and runoff $(R)$ are shown in Figs. 9-11. Note that because of the lack of observational data, evaporation has been diagnosed as $E=P-R$ by assuming that the long-term storage of soil water is negligible. The observational values used to calculate the biases are given in Table 2. In addition to the used GPCP precipitation, CMAP precipitation is also given to pay regard to the uncertainty related to the gridded precipitation datasets over land (cf. section 3a).

As to be expected from Figs. 1a and 2, there is a positive precipitation bias in most catchment areas. Exceptions are the Danube and Murray Rivers. The errors are largest for Ganges/Brahmaputra and Yangtze Kiang caused by excessive monsoon precipitation at the southern slope of the Himalayas (cf. Fig. 5). In most cases, the L31 simulations are more realistic. Substan- 


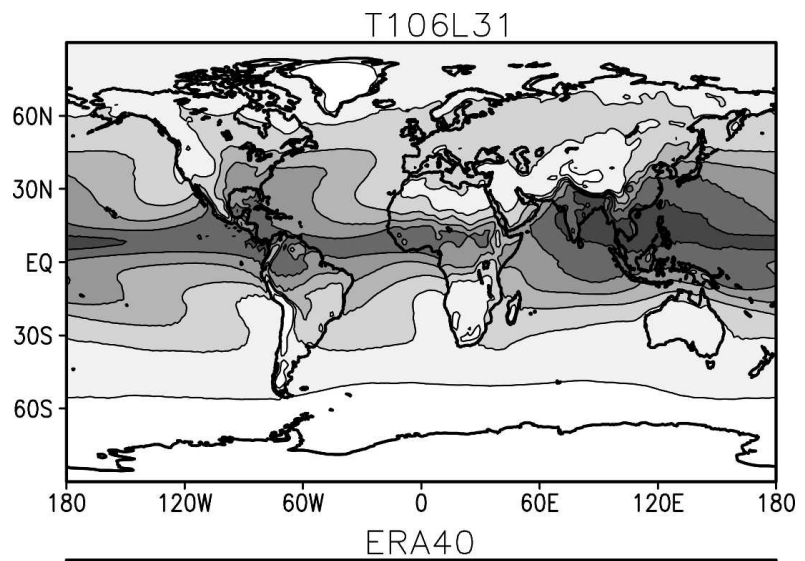

than the vertical resolution effect. The highest resolution model configuration (T159L31) performs best in 5 out of 12 catchments (Congo, Danube, Mississippi, Nile, and Yangtze Kiang). The evaporation biases shown in Fig. 10 are in most respects similar to those in precipitation though the advantages of increased vertical resolution are less obvious than for precipitation. Runoff biases (Fig. 11), on the other hand, are substantially improved in the L31 simulations for the Congo, Danube, Ganges/Brahmaputra, Nile, Parana, and Yangtze Kiang, whereas no systematic changes are found for the Arctic rivers, Amur, Baltic Sea, Mississippi, and Murray. For the Amazon, the L31 resolution leads to a reduction in the runoff, which increases the bias of the L31 simulations compared to the corresponding L19 simulations. Higher horizontal resolution is beneficial only for the Amazon, Baltic Sea, Danube, and Yangtze Kiang. In the Nile catchment, runoff biases exceed $300 \%$ in all L19 simulations, which is caused by the overestimation of precipitation (Fig. 9). These biases are considerably reduced in the L31 simulations, but they are still large, probably because of the fact that a substantial part of the Nile water is not available for runoff but used for irrigation. The Murray catchment covers a very dry area with an annual discharge of only $8 \mathrm{~km}^{3} \mathrm{a}^{-1}\left(=258 \mathrm{~m}^{3} \mathrm{~s}^{-1}\right)$. As there are negative biases in precipitation for all model resolutions, even comparatively small deviations (ranging from 2 to $6 \mathrm{~km}^{3} \mathrm{a}^{-1}$ ) of $P-E$ (= runoff) from the observed discharge may cause relatively large relative runoff biases.

In conclusion, the improved hydrological cycle in the L31 simulations is to some extent caused by more realistic recycling of water through local evaporation, but caused primarily by atmospheric dynamics (note that, in the long-term mean, runoff is equivalent to vertically integrated moisture convergence). This is consistent with the findings of Roeckner et al. (2006), who showed that atmospheric dynamics and thermodynamics improved substantially at higher vertical resolution (L31).

Figure 12 compares simulated and observed annual

FIG. 7. Geographic distributions of simulated IWV [(top) T106L31] and observational estimates of IWV [(middle) ERA-40 and (bottom) NVAP] in the boreal summer (JJA) for the time period 1988-99. Unit: $\mathrm{mm}$.

tial improvements compared to L19 are achieved for five catchments (Amazon, Congo, Danube, Nile, and Parana). The biases are significantly reduced also for Ganges/Brahmaputra and Yangtze Kiang, but they still remain rather large. Little change is found for the Arctic rivers, Amur, Mississippi, and Murray. A slight deterioration in the L31 simulations is found only for the Baltic Sea catchment. The impact of changed horizontal resolution is comparatively small and less systematic cycles of precipitation for the 12 catchments shown in Fig. 8. Here, we focus on the impact of horizontal and vertical resolution on the simulation of the annual cycle. Note also that CMAP and GPCP data differ (cf. section 3a), particularly at high northern latitudes. A common feature of all simulations is that precipitation in the boreal summer is overestimated, especially in the monsoon regions, and also during the rainy season in the Tropics (Amazon and Congo). In most catchments the amplitude of the annual cycle is too large. The beneficial effect of a higher vertical resolution on the annual mean precipitation (cf. Fig. 9) can also be noticed 


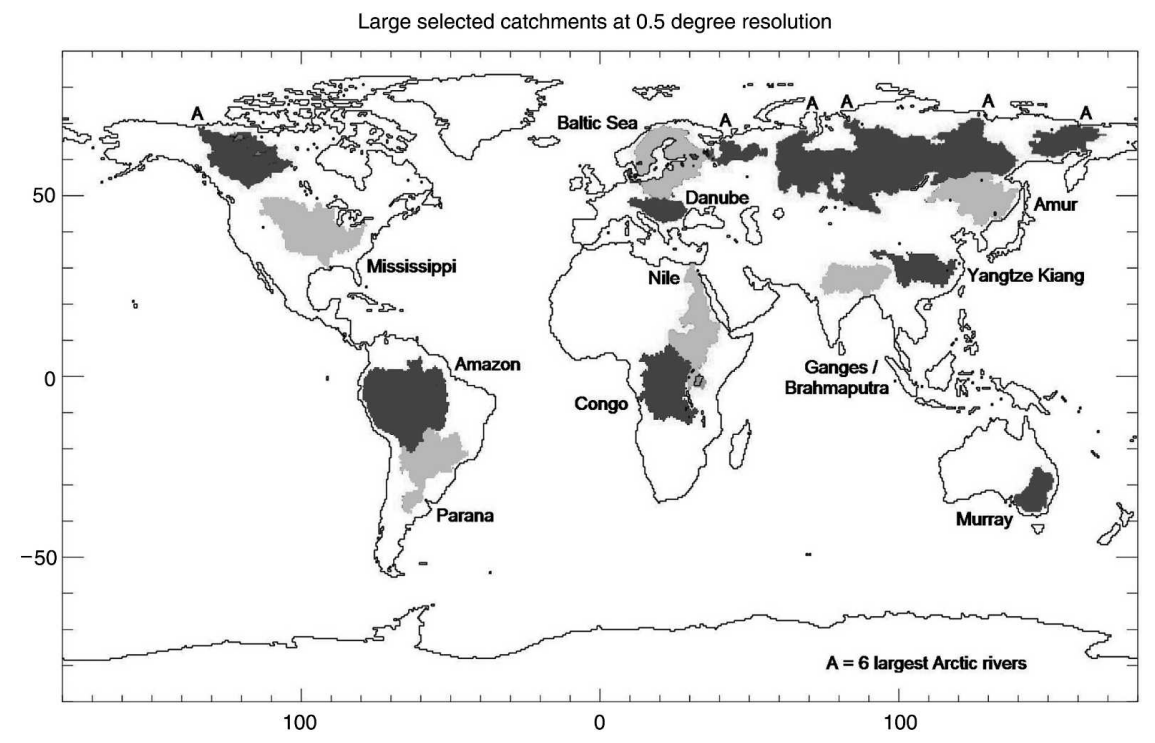

FIG. 8. Selected large catchments of the globe at $0.5^{\circ}$ resolution.

in the annual cycles. This is evident for the Amazon, Congo, Ganges/Brahmaputra, Nile, Parana, Yangtze Kiang, and Baltic Sea. For the Danube, the main difference compared to L19 is an increased precipitation throughout the year resulting in a realistic annual mean value (cf. Fig. 9). Precipitation in the summer and the fall is systematically higher than in the L19 simulations but still somewhat low compared to GPCP and CMAP. For the Danube, an increased horizontal resolution seems to be beneficial as well. In fact, the most realistic simulation of the annual cycle is obtained at high resolutions (T106L31 and also T159L31; not shown). Minor improvements of the annual cycle at higher horizontal resolution can also be found for the Baltic Sea, Nile,

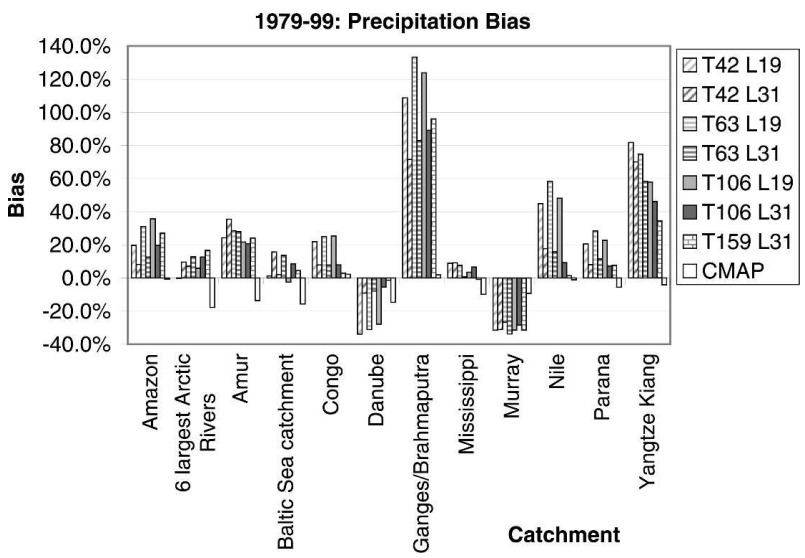

FIG. 9. Annual mean bias in simulated precipitation over several catchments. The bias was calculated from the difference of the simulated precipitation minus GPCP data.

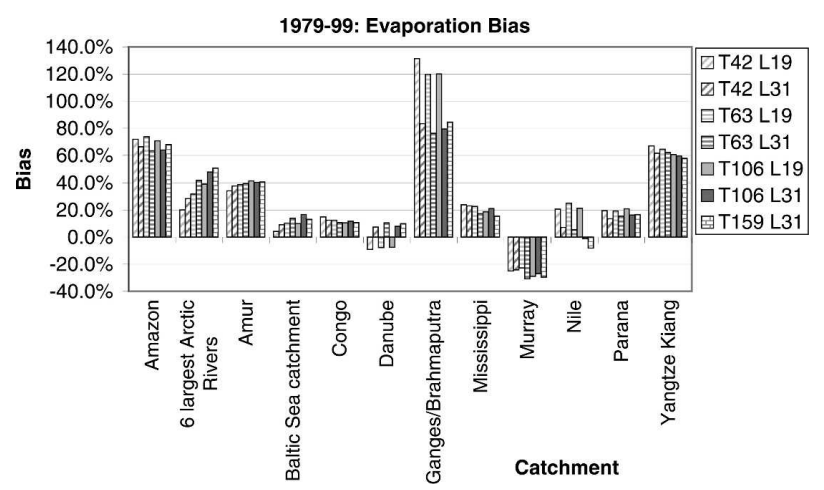

FIG. 10. Annual mean bias in simulated evaporation over several catchments. The observed evaporation was calculated from the difference of GPCP precipitation and observed climatological discharge (Dümenil Gates et al. 2000).

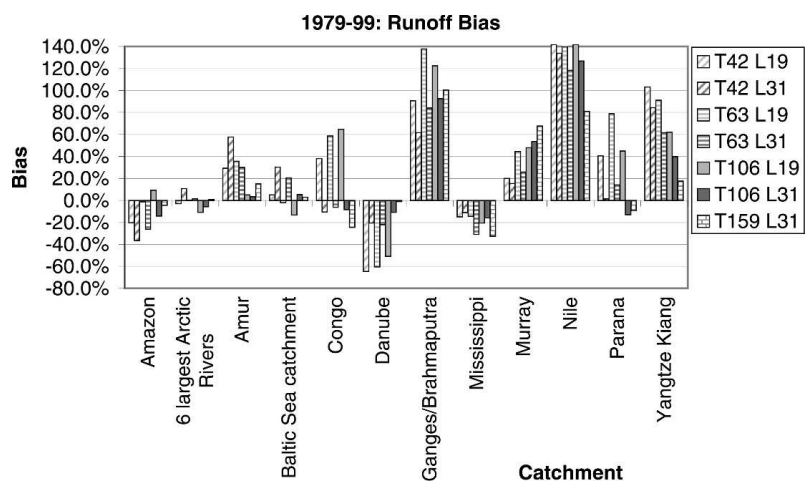

FIG. 11. Annual mean bias in simulated runoff over several catchments. The bias was calculated from the difference of the simulated runoff and the observed climatological discharge. 
TABLE 2. Observed values for CMAP and GPCP precipitation (1979-99), evaporation (GPCP precipitation minus climatological discharge), and discharge (climatological). Unit: $\mathrm{mm} \mathrm{a}^{-1}$.

\begin{tabular}{lcccc}
\hline \hline \multicolumn{1}{c}{ Catchment } & $\begin{array}{c}\text { CMAP } \\
\text { precipitation }\end{array}$ & $\begin{array}{c}\text { GPCP } \\
\text { precipitation }\end{array}$ & Evaporation & Discharge \\
\hline Amazon & 1866 & 1879 & 819 & 1053 \\
6 largest Arctic rivers & 403 & 490 & 242 & 204 \\
Amur & 520 & 602 & 382 & 179 \\
Baltic Sea catchment & 630 & 747 & 409 & 279 \\
Congo & 1496 & 1463 & 5114 & 365 \\
Danube & 709 & 1028 & 402 & 252 \\
Ganges/Brahmaputra & 1048 & 834 & 610 & 636 \\
Mississippi & 752 & 564 & 529 & 183 \\
Murray & 511 & 630 & 578 & 8 \\
Nile & 623 & 1275 & 972 & 49 \\
Parana & 1203 & 1069 & 510 & 268 \\
Yangtze Kiang & 1025 & & 537 \\
\hline
\end{tabular}

and Yangtze Kiang. No systematic resolution dependence is found for the Arctic rivers, Amur, Mississippi, and Murray.

Over many land areas, precipitation and surface temperature are negatively correlated. For example, surface temperature drops after the onset of the summer monsoons and during the rainy seasons in the Tropics. Similar effects occur at middle latitudes during the summer season. Therefore, it could be expected that biases in precipitation and surface air temperature are negatively correlated as well.

Figure 13 shows annual cycles of model biases in surface air temperature for a subset of eight catchments. For example, the Amazon and Congo basins are somewhat cold and wet during much of the rainy season but too warm shortly after the end of the dry season during which the simulated precipitation is too low. In the Danube catchment, summer precipitation in the L19 simulations is severely underestimated (cf. Fig. 12), while temperatures are too high by about $2^{\circ} \mathrm{C}$. In the L31 simulations, on the other hand, summer precipitation is higher, and more realistic, while temperature errors are below $1^{\circ} \mathrm{C}$. For the Nile catchment, both precipitation and temperature are realistically simulated at L31 resolution, whereas precipitation is too high and temperature too low in the L19 simulations. An exception is the Mississippi catchment where both precipitation and temperature during the summer are higher at L19 than at L31 vertical resolution and are also too high compared to observations.

The annual cycles of surface air temperature and precipitation can also be assessed through a classification of surface climate (Köppen 1923) shown in Fig. 14 for both the model and the observations (both at T106 horizontal resolution). The climate zones are defined in Table 3. Although the model is able to faithfully rep- resent the geographic distribution of the climate zones, there are a few notable exceptions that can largely be attributed to errors in simulated precipitation. For example, the climate zones over Australia are systematically shifted toward a drier climate, that is, desert climate covers a too large area, and the areal extent of savanna climate in northern Australia and temperate climate in eastern Australia are too small. All this is consistent with a lack of precipitation, especially during the wet season (cf. Fig. 4), and also with too little precipitation in the Murray catchment (cf. Fig. 9). Also noteworthy is the failure of the model to represent the rainforest climate in Central Africa. This is most likely caused by a lack of precipitation in the Congo catchment during the dry season (cf. Figs. 5 and 12). The desert regions are somewhat more extended than in the observations, not only in Australia but also in parts of Asia, Somalia, and Namibia. On the other hand, many regional details are well represented in the model simulation. It is interesting to note that the most noticeable errors in the T106L31 simulation, that is, the overestimation of the desert area and the underestimation of the rainforest area are significantly smaller in the T159L31 simulation (not shown). The relative errors in areal extent are reduced by $17 \%$ for the rainforest climate and $16 \%$ for the desert climate.

\section{Precipitation response to ENSO}

The El Niño-Southern Oscillation (ENSO) phenomenon is the most prominent mode of interannual variability in the atmosphere and in the ocean. The center of action is in the equatorial Pacific. However, the consequences of ENSO are not restricted to this area, but anomalies in atmospheric circulation, temperature, and 
(a)

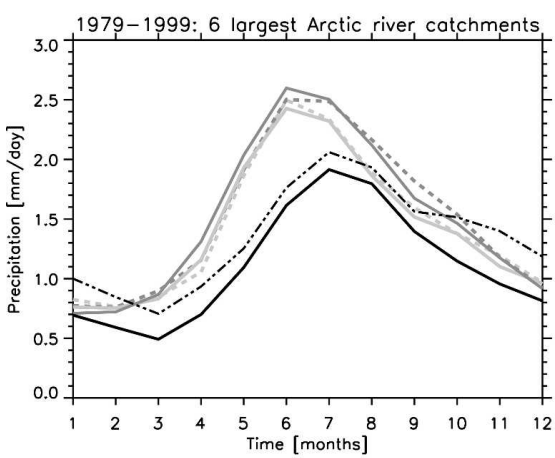

(c)

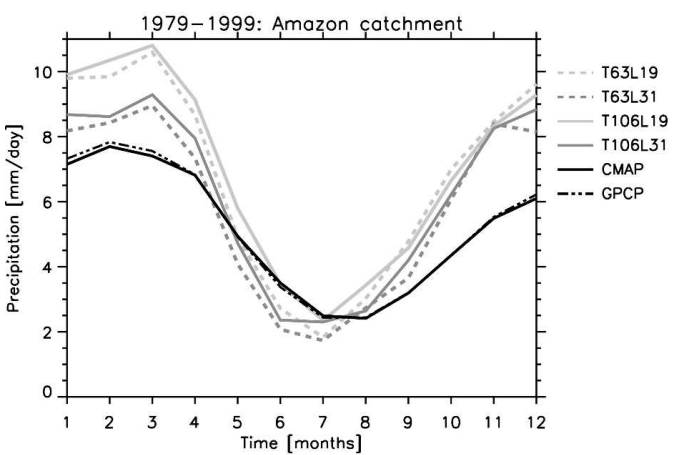

(e)

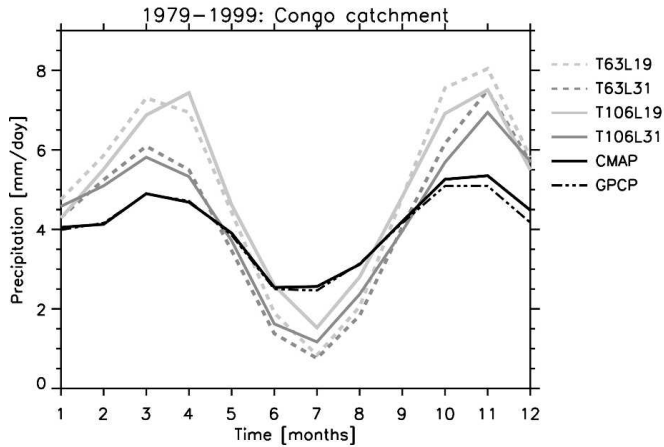

(g)

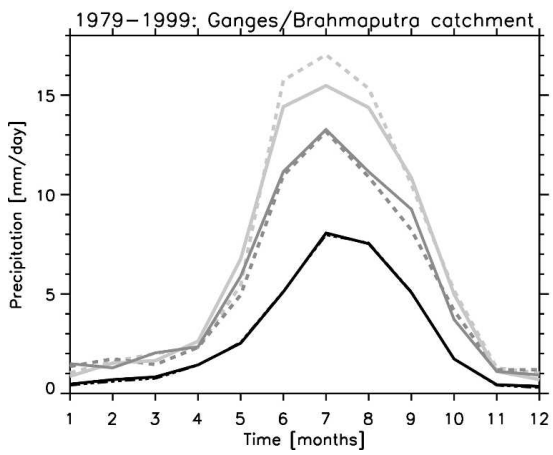

(b)

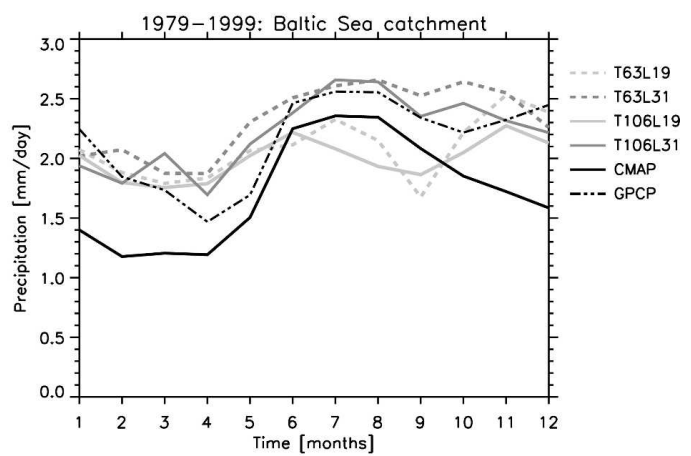

(d)

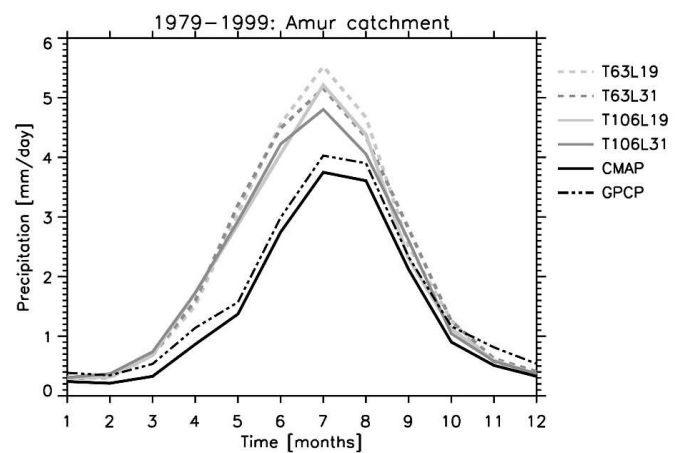

(f)

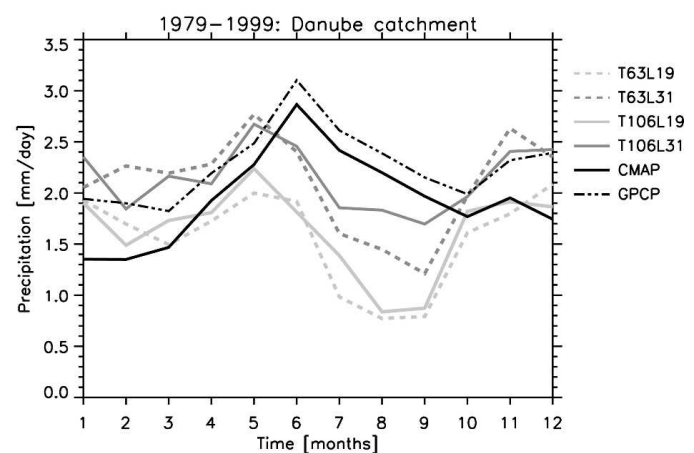

(h)

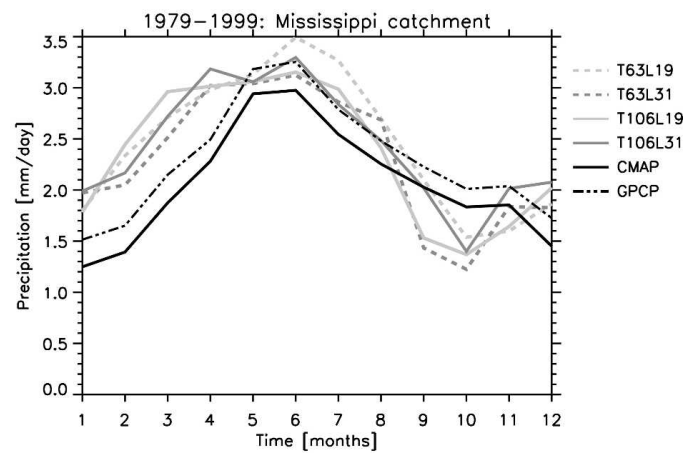

FIG. 12. Simulated and observed mean annual cycle of precipitation within the catchments defined in Fig. 6. Unit: $\mathrm{mm} \mathrm{day}^{-1}$. 
(i)

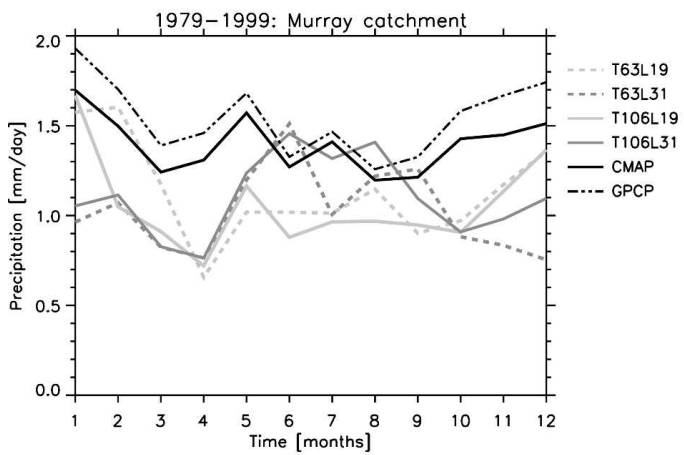

(k)

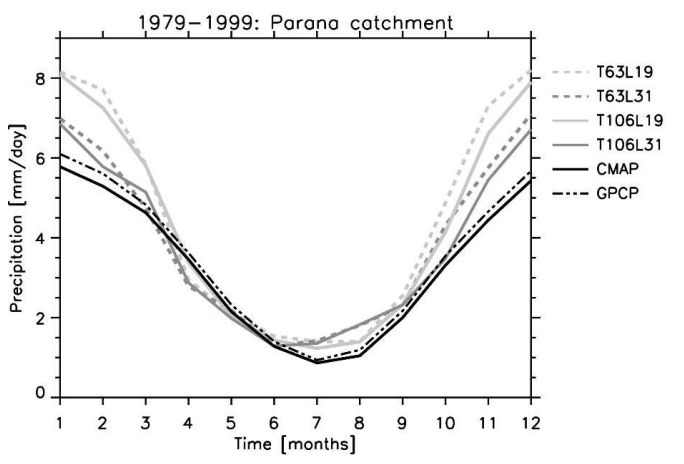

(j)

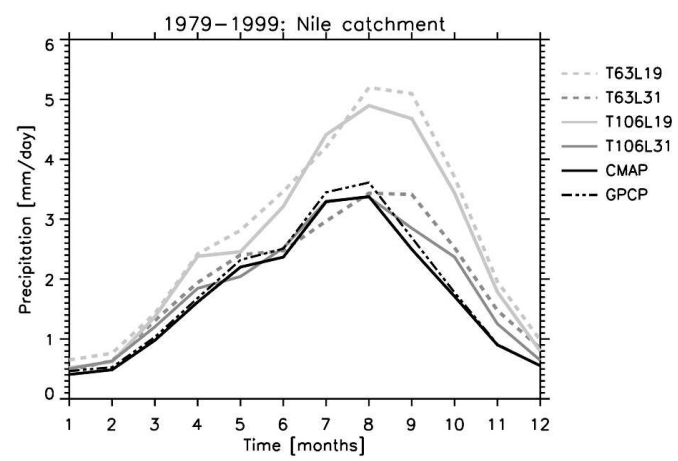

(I)

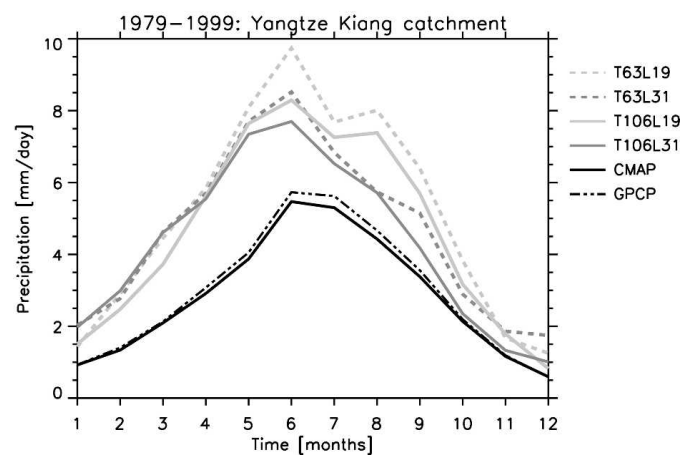

FIG. 12. (Continued)

precipitation can be noticed worldwide (e.g., Ropelewski and Halpert 1987). Therefore, analyzing the model response to ENSO provides a useful framework for assessing the simulated hydrological cycle on interannual time scales (Hack et al. 1998).

In this section the precipitation response to warm (El Niño) and cold (La Niña) SST episodes in the equatorial Pacific in the ECHAM5/T106L31 model configuration is compared to observations (CMAP data). Figure 15 shows a Hovmöller diagram of simulated and observed monthly precipitation anomalies along the equator $\left(5^{\circ} \mathrm{S}-5^{\circ} \mathrm{N}\right)$ for the time period $1979-98$. As to be expected, positive anomalies in the central and eastern Pacific are simulated and observed during warm episodes, and most pronounced during the winter months of 1982/83 and 1997/98. Negative anomalies are found during cold episodes such as 1988/89 and 1995/96. Although the model is able to capture the temporal evolution of monthly precipitation anomalies in the tropical Pacific reasonably well, the amplitude of the variations is somewhat larger than observed.

Figure 16 shows a composite map of simulated and observed precipitation anomalies during the mature phase of El Niño (DJF mean 1982/83, 1986/87, 1991/92, $1992 / 93$, and $1997 / 98$ as a departure from the climato- logically DJF mean 1979-98). Positive anomalies are simulated and observed in the central and eastern $\mathrm{Pa}-$ cific with peak values of more than $5 \mathrm{~mm}$ day $^{-1}$. The tropical Pacific pattern with negative anomalies both northward and southward of the positive anomaly are indicative of an equatorward shift of the intertropical convergence zone and the South Pacific convergence zone, respectively, which tend to merge into a huge convective complex centered at the equator during the mature phase of El Niño. Associated with the shift of the convection zone is a weakening and eastward displacement of the Walker cell, while the Hadley cell moves equatorward and intensifies (not shown). The simulated remote response is broadly similar to that inferred from CMAP data, with positive anomalies in the East China Sea, at the Californian coast, and in a belt extending from the eastern Pacific across the $\mathrm{Ca}$ ribbean Sea and U.S. Gulf Coast into the Atlantic Ocean. The negative anomalies over northeastern Brazil found in CMAP are also captured in the simulation. On the other hand, the region of negative anomalies in the Maritime Continent is less coherent in the model than in the CMAP data, and the model fails to simulate the observed pattern in the Indian Ocean and Africa. The underestimation of negative anomalies in northern 

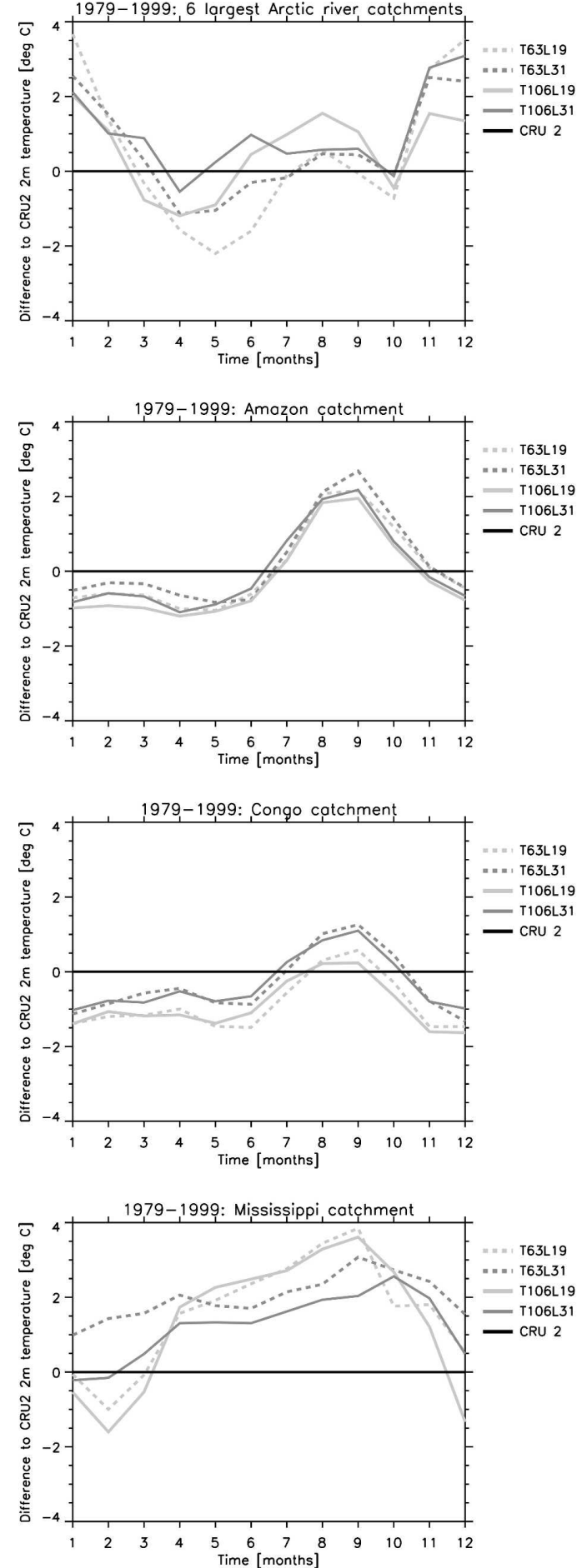
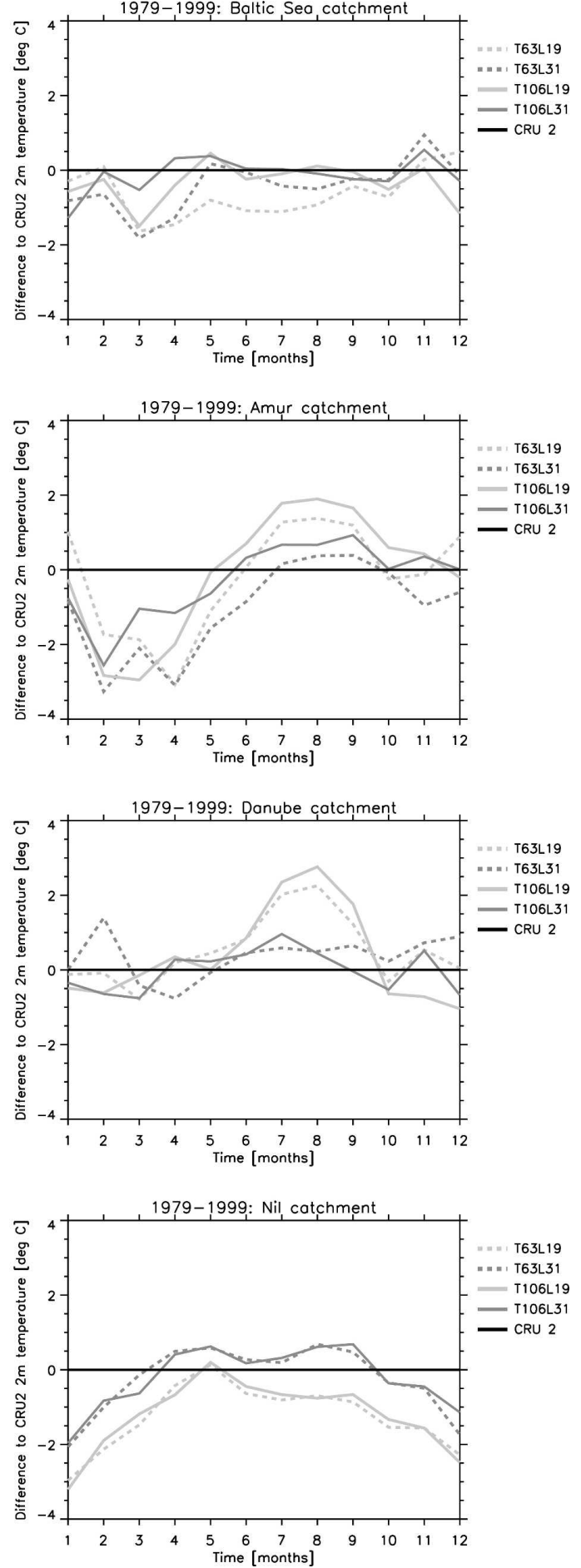

FIG. 13. Differences of monthly surface air $(2 \mathrm{~m})$ temperature between model simulations and CRU 2 data (Mitchell et al. 2004, manuscript submitted to J. Climate). Unit: ${ }^{\circ} \mathrm{C}$.

Australia is probably caused by the negative precipitation bias in the T106L31 simulation (cf. Fig. 4). In most regions, however, the amplitude of the response is somewhat larger than observed, which is also consistent with the overestimated precipitation amount in most regions (cf. section 3 ).

Figure 17 shows a composite map of simulated and observed precipitation anomalies for cold episodes 
T106L31
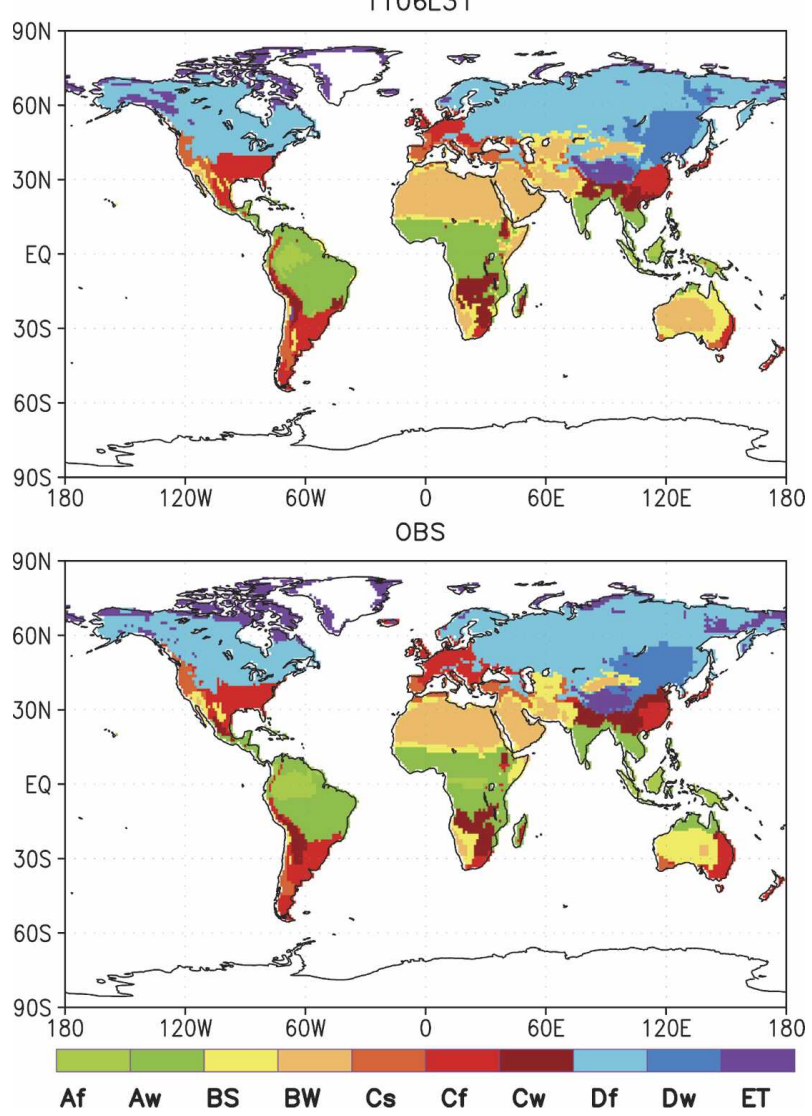

FIG. 14. (top) Simulated (T106L31) and (bottom) "observed" climate zones according to Köppen (1923) for the period 1979-99. The observed climate zones were derived from climatological annual cycles of GPCP precipitation and CRU 2 temperature data.

(DJF mean 1983/84, 1984/85, 1988/89, and 1995/96 as a departure from the climatological DJF mean 1979-98). In most regions the precipitation response to cold episodes is a mirror image of the response to warm episodes, supporting the view that interannual variations of precipitation at lower latitudes are largely driven by SST anomalies in the equatorial Pacific. This can also be inferred from teleconnection maps, revealing the correlation between Niño-3 SST and precipitation at each grid point during DJF (not shown). According to theses analyses, correlation coefficients $>40 \%$ and $<40 \%$ are widespread.

The broad pattern of the precipitation response to ENSO is captured in all ECHAM5 simulations, and the sensitivity to resolution is small for most regions. This can also be seen in Table 4, which shows the correlation between simulated and observed precipitation for seven areas. These include the eastern equatorial $\mathrm{Pa}$ cific $\left(12^{\circ} \mathrm{S}-8^{\circ} \mathrm{N}, 160^{\circ} \mathrm{E}-90^{\circ} \mathrm{W}\right)$, the Maritime Continent $\left(15^{\circ} \mathrm{S}-15^{\circ} \mathrm{N}, 120^{\circ}-150^{\circ} \mathrm{E}\right)$, the North Pacific trade wind region $\left(15^{\circ}-30^{\circ} \mathrm{N}, 135^{\circ} \mathrm{E}-135^{\circ} \mathrm{W}\right)$, Brazil including neighboring countries to the north $\left(8^{\circ} \mathrm{S}-12^{\circ} \mathrm{N}, 70^{\circ}-\right.$ $\left.45^{\circ} \mathrm{W}\right)$, the western equatorial Indian Ocean $\left(5^{\circ} \mathrm{S}-5^{\circ} \mathrm{N}\right.$, $\left.40^{\circ}-60^{\circ} \mathrm{E}\right)$, the southern United States including part of Mexico $\left(25^{\circ}-35^{\circ} \mathrm{N}, 120^{\circ}-70^{\circ} \mathrm{W}\right)$, and central Europe $\left(50^{\circ}-55^{\circ} \mathrm{N}, 5^{\circ}-15^{\circ} \mathrm{E}\right)$. For the southern United States and Mexico, Brazil, and central Europe only grid points over land are included. In all simulations the highest correlation $(>0.9)$ is found in the eastern equatorial Pacific. The correlations are relatively high in the other regions ( $>0.4$ in the ensemble means), except for central Europe with correlations around zero. In most areas the deviations from the ensemble mean are small. An exception is the Indian Ocean, where the correlations at T106L31 and T63L31 resolution are clearly smaller than the ensemble mean. Although a systematic increase or decrease of the correlation with changing resolution is not discernible, the highest correlations in the respective areas are often found at lower horizontal resolution (T42). Since the total variance is very similar in the experiments (not shown), we conclude that, at higher resolution, a larger fraction of interannual variability in the high-resolution experiments is not forced by the SST variability.

ENSO is also known to be the largest climatic forcing of interannual monsoon variability. Numerous studies have demonstrated that the Indian monsoon rainfall tends to be below (above) normal in the developing phase of a warm (cold) ENSO event (e.g., Ropelewski and Halpert 1987; Sperber and Palmer 1996; Krishna Kumar et al. 1999). During an El Niño event the rising branch of the Walker circulation normally located in the western Pacific shifts to the central and eastern Pacific. Consequently, there is anomalous subsidence and anomalously low precipitation in an area extending from the western Pacific to the Indian subcontinent.

High correlations between ENSO and monsoon variability were found when the monsoon strength was defined by dynamical quantities like the Webster-Yang index (Webster and Yang 1992). When all-India precipitation was used as an index the correlations became weaker (e.g., Arpe et al. 1998). A clear signal in several GCMs was found for the 1987 warm episode that was associated with a very weak monsoon and for the 1988 cold episode that was associated with a strong monsoon (Sperber and Palmer 1996). However, this was evident only for those models that were able to realistically capture the teleconnection pattern of the observed allIndia rainfall index with SST.

Table 5 shows a comparison of observed and simulated all-India rainfall in the summer monsoon season [JJA-September (JJAS)] of 1987 and 1988. The simulated precipitation is systematically larger than in the two observational datasets [GPCP and Climate Re- 
TABLE 3. Climate classification after Köppen (1923) based on climatological annual cycles of surface air temperature $(T)$ and precipitation $(P)$ for the years 1979-99. Here, $T_{\max }$ and $T_{\min }$ denote the temperature of the warmest and coldest month, $P_{\min }$ the precipitation of the driest month, and $P_{\mathrm{ann}}$ the annual mean precipitation; $P_{\mathrm{smax}}, P_{\mathrm{smin}}, P_{\mathrm{wmax}}$, and $P_{\mathrm{wmin}}$ are the precipitation of the wettest summer month, driest summer month, wettest winter month, and driest winter month, respectively; $P_{d}$ is a dryness threshold, which depends on the annual mean temperature $T_{\text {ann }}\left({ }^{\circ} \mathrm{C}\right)$ and on the annual cycle of precipitation:

$$
\begin{aligned}
P_{d}\left[\mathrm{~cm} \mathrm{month}^{-1}\right] & =2 T_{\text {ann }} & & \text { if at least } 70 \% \text { of the annual precipitation occurs in the winter } \\
& =2 T_{\text {ann }}+28 & & \text { if at least } 70 \% \text { of the annual precipitation occurs in the summer } \\
& =2 T_{\text {ann }}+14 & & \text { otherwise. }
\end{aligned}
$$

\begin{tabular}{lll}
\hline \hline Type & \multicolumn{1}{c}{ Name } & \multicolumn{1}{c}{ Criterion } \\
\hline A & Tropical rainy climates & $T_{\min } \geq 18^{\circ} \mathrm{C}$ \\
Af & Tropical rainforest climate & $P_{\min } \geq 6 \mathrm{~cm}_{\operatorname{month}}^{-1}$ \\
Aw & Tropical savanna climate & $P_{\min } \leq 6 \mathrm{~cm}$ month \\
B & Dry climates & $P_{\text {ann }} \leq P_{d}$ \\
BS & Steppe climate & $P_{\text {ann }} \geq 0.5 P_{d}$ \\
BW & Desert climate & $P_{\text {ann }}<0.5 P_{d}$ \\
C & Humid mesothermal climates & $-3^{\circ} \mathrm{C} \leq T_{\min } \leq 18^{\circ} \mathrm{C}$ \\
Cs & Warm with dry summer & $P_{\text {wmax }} \geq 3 P_{\text {smin }}$ \\
Cw & Warm with dry winter & $P_{\text {wmax }} \geq 10 P_{\text {wmin }}$ \\
Cf & Humid temperate climate & $P_{\text {wmax }}<10 P_{\text {wmin }}$ and $P_{\text {wmax }}<3 P_{\text {smin }}$ \\
D & Humid microthermal climates & $T_{\min }<-3^{\circ} \mathrm{C}$ and $T_{\max } \geq 10^{\circ} \mathrm{C}$ \\
Dw & Cold with dry winter & $P_{\text {smax }} \geq 10 P_{\text {wmin }}$ \\
Df & Cold with moist winter & $P_{\text {smax }}<10 P_{\text {wmin }}$ \\
E & Polar climates & $T_{\max }<10^{\circ} \mathrm{C}$ \\
ET & Tundra climate & $0^{\circ} \mathrm{C} \leq T_{\max }<10^{\circ} \mathrm{C}$ \\
EF & Permafrost climate & $T_{\max }<0^{\circ} \mathrm{C}$ \\
\hline
\end{tabular}
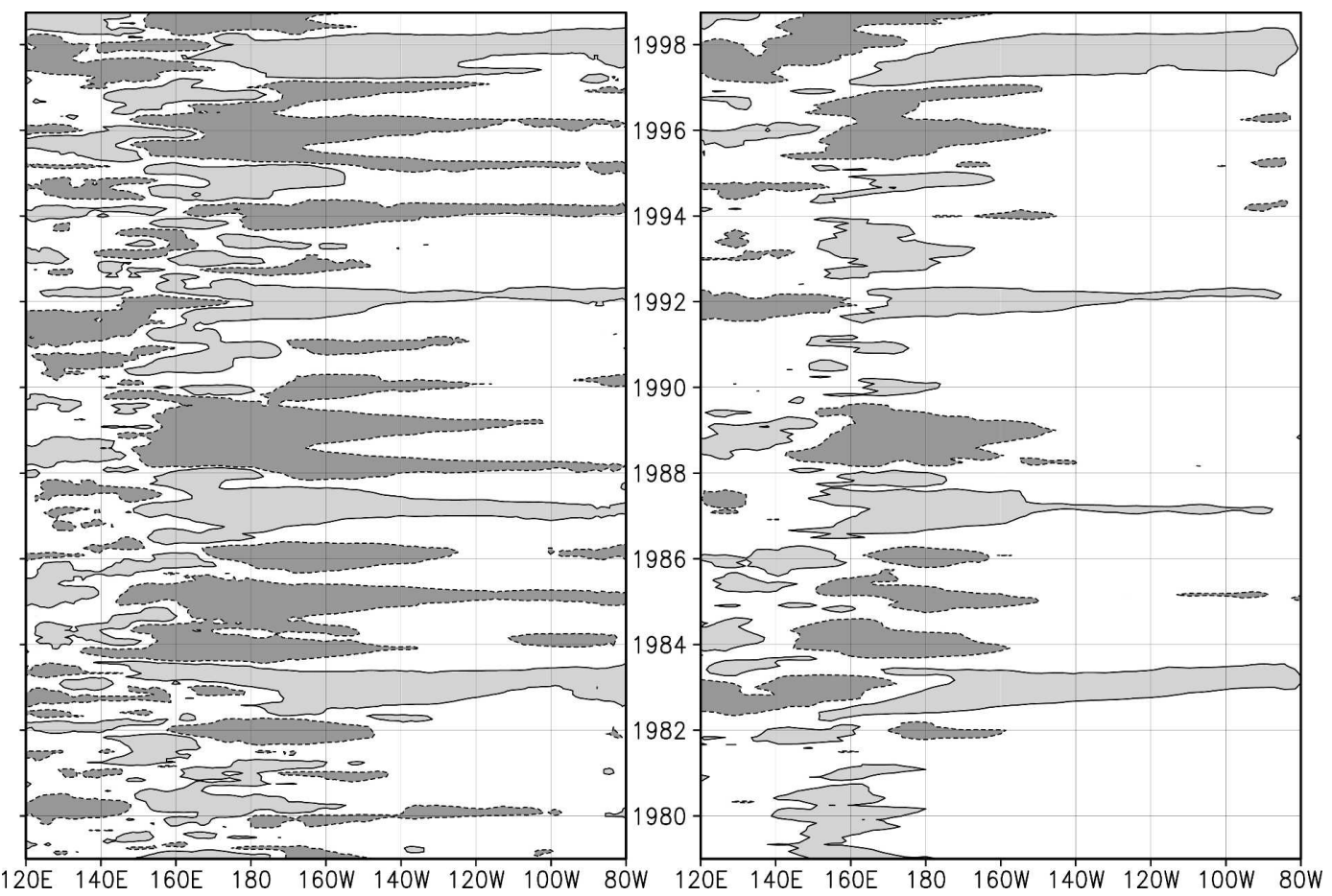

FIG. 15. Hovmöller diagrams of (left) simulated (T106L3) and (right) observed (CMAP) monthly precipitation anomalies $\left(\mathrm{mm} \mathrm{day}^{-1}\right)$ along the equator $\left(5^{\circ} \mathrm{S}\right.$ to $\left.5^{\circ} \mathrm{N}\right)$. The light shading marks positive anomalies $(>+2 \mathrm{~mm}$ day $\left.^{-1}\right)$; the dark shading marks negative anomalies $\left(<-2 \mathrm{~mm} \mathrm{day}^{-1}\right)$. 
T106L31
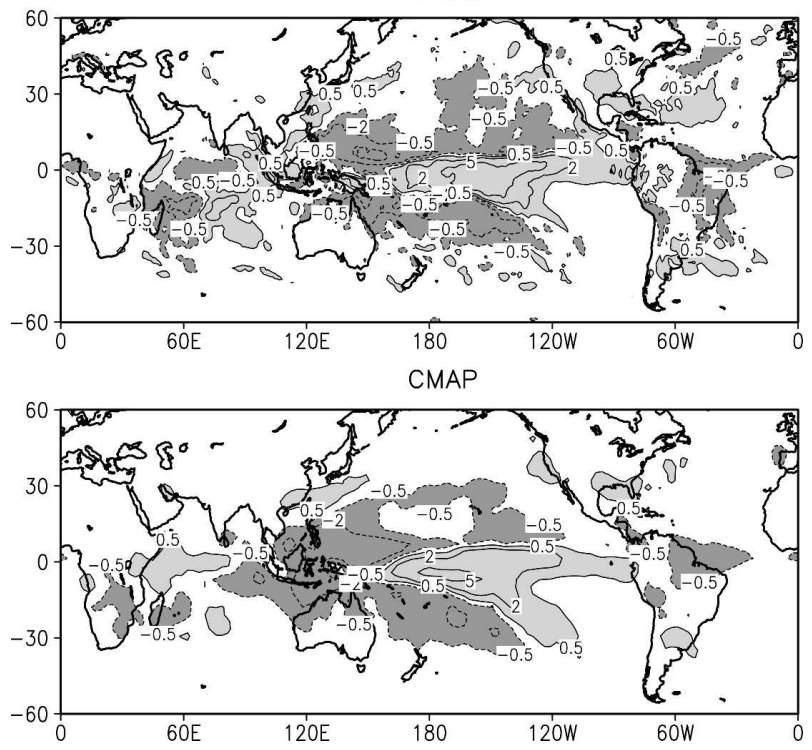

FIG. 16. (top) Simulated (T106L31) and (bottom) observed (CMAP) composite precipitation response in the boreal winter (DJF) to five warm episodes in the tropical East Pacific (see text) during the time period 1979-98. The light shading marks positive anomalies $\left(>+0.5 \mathrm{~mm} \mathrm{day}^{-1}\right)$; the dark shading marks negative anomalies $\left(<-0.5 \mathrm{~mm} \mathrm{day}^{-1}\right)$.

search Unit (CRU); New et al. 2000]. In observations and simulations, the rainfall in 1988 (La Niña year) is generally higher than in the El Niño year 1987. A systematic resolution dependence cannot be seen. Apart from the T42 simulations, which fail to simulate the correct sign of the response, the relative change is smaller than observed at the highest (T159L31) and lowest (T63L19) resolution, respectively, but larger than observed at intermediate resolutions (T106L31 and T63L31). However, these results should be viewed with caution because the identification of resolution dependence would require a good assessment of internal dynamics from an ensemble of realizations at the respective resolution (e.g., Sperber and Palmer 1996).

Considering the whole period of $20 \mathrm{yr}$ of simulation, there is no significant correlation between simulated
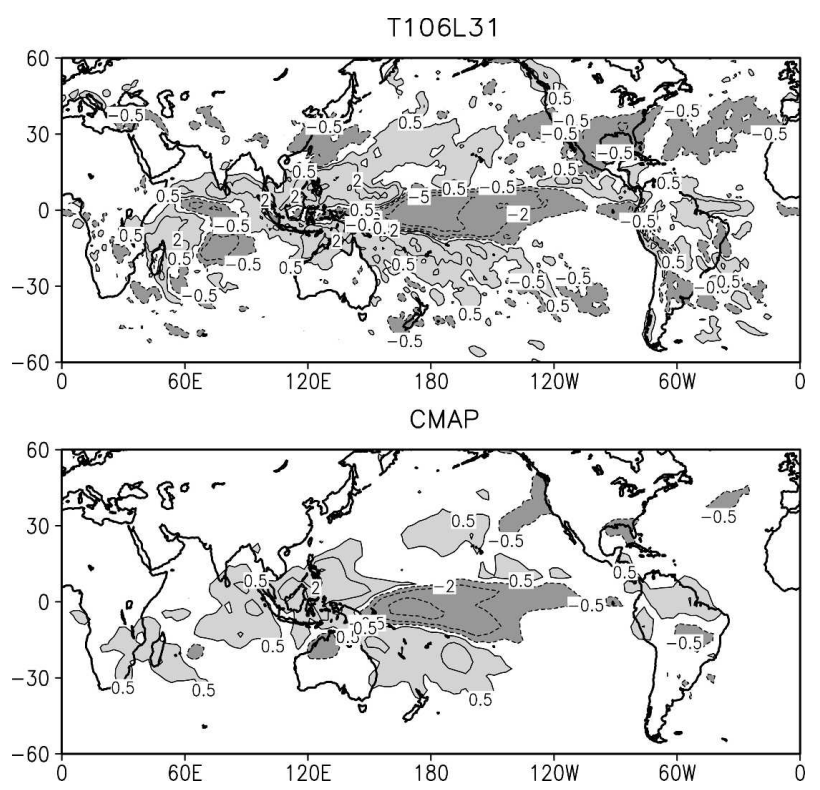

FIG. 17. Same as in Fig. 16, but for four cold episodes in the tropical East Pacific.

precipitation and GPCP data over the Indian subcontinent and the Indian Ocean. This is consistent with findings of Arpe et al. (1998), who looked for reasons for this failure and suspected among others the missing two-way interaction between ocean and atmosphere over the Indian Ocean in uncoupled experiments. This suspicion has been confirmed by Wu and Kirtman (2004) who demonstrated the importance of a local coupled air-sea feedback in the Indian Ocean for an adequate simulation of the Indian monsoon-ENSO relationship.

\section{Summary and concluding remarks}

We have discussed selected aspects of the hydrological cycle in ECHAM5 model simulations forced with observed monthly SST at different horizontal and vertical resolutions. On the global scale both precipitation and evaporation are smaller at higher vertical resolution (L31 versus L19) over land, in better agreement with observations. Oppositely, both fluxes increase in

TABLE 4. Correlation between observed and simulated DJF precipitation for selected areas (see text). Boldface denotes the largest correlation in the respective area.

\begin{tabular}{lccccccc}
\hline \hline \multicolumn{1}{c}{ Area } & T159L31 & T106L31 & T63L31 & T63L19 & T42L31 & T42L19 & Mean \\
\hline East equatorial Pacific & 0.93 & 0.93 & $\mathbf{0 . 9 5}$ & 0.93 & 0.92 & 0.93 & 0.93 \\
Maritime Continent & 0.56 & 0.56 & 0.55 & 0.53 & $\mathbf{0 . 7 7}$ & 0.74 & 0.62 \\
North Pacific trades & 0.63 & 0.64 & 0.68 & 0.55 & 0.59 & $\mathbf{0 . 8 2}$ & 0.65 \\
Brazil & 0.73 & 0.72 & 0.79 & 0.70 & 0.68 & $\mathbf{0 . 7 7}$ & 0.73 \\
West equatorial Indian Ocean & 0.48 & 0.29 & 0.08 & 0.63 & $\mathbf{0 . 7 2}$ & 0.54 & 0.46 \\
South United States + Mexico & 0.46 & 0.45 & 0.39 & $\mathbf{0 . 5 6}$ & 0.31 & 0.46 & 0.44 \\
Central Europe & 0.06 & -0.40 & 0.11 & 0.16 & $\mathbf{0 . 3 1}$ & 0.20 & 0.07 \\
\hline
\end{tabular}


TABLE 5. All-India summer precipitation in observations and simulations. Unit: $m m$ day $^{-1}$.

\begin{tabular}{lcccccrrr}
\hline \hline Year & GPCP & CRU & T159L31 & T106L31 & T63L31 & T63L19 & T42L31 & T42L19 \\
\hline 1987 & 4.7 & 5.4 & 7.7 & 6.1 & 7.2 & 9.7 & 10.4 & 9.7 \\
1988 & 6.2 & 6.8 & 9.4 & 9.6 & 10.1 & 10.8 & 9.1 & 8.1 \\
Diff $(\%)$ & 32 & 26 & 22 & 57 & 40 & 11 & -12 & -16 \\
\hline
\end{tabular}

the L31 simulations over the ocean, most pronounced at low latitudes.

The main focus is on the validation of precipitation over land, for which the quality of observational estimates is far better than over the ocean. For this purpose a number of large catchments has been selected representing the major river systems on earth in different climate zones. In almost all catchments, increasing vertical resolution is more beneficial than increasing horizontal resolution. At the highest resolutions (T106L31 and T159L31) the precipitation bias is below $10 \%$ in $50 \%$ of all catchments. In all simulations, the largest errors are found in the catchments of Ganges/ Brahmaputra and Yangtze Kiang. This is caused by excessive precipitation during the summer monsoon at the southern slope of the Himalayas. The vertical resolution effect on the evaporation is smaller than on the runoff. This indicates that the reductions in the precipitation bias are caused primarily by an improved moisture transport, which is closely related to the runoff in the long-term mean. The beneficial impact of an increased vertical resolution on the thermodynamic structure of the troposphere, and specifically on the vertical moisture transport, has been discussed in detail by Roeckner et al. (2006). These improvements are largely due to the smaller numerical diffusion at higher vertical resolution so that a larger, and also more realistic, vertical moisture gradient can be maintained throughout the troposphere. It is speculated that the sensitivity of the hydrological cycle to the vertical resolution is closely related to the tropospheric moisture changes caused by a more accurate vertical moisture transport at higher vertical resolution.

In many catchments, the amplitude of the annual cycle is too large, with higher-than-normal precipitation during the summer months (high northern latitudes and Asian monsoon) and also during the rainy season in the Tropics (Amazon, Congo, and Nile). Except for the high-latitude catchments, this bias is considerably reduced in the L31 simulations, which is most evident for the Nile catchment. Also associated with these improvements is a systematic reduction in the surface air temperature bias, which is smaller than $2^{\circ} \mathrm{C}$ in the T106L31 model configuration, with only a few exceptions in single months.

By combining the climatological annual cycles of pre- cipitation and surface air temperature, we have shown that the model is able to capture not only the observed large-scale distribution of climate zones but also many regional details. The most notable deficiencies are a too large extent of desert climate, especially in Australia, where precipitation is generally too low, and the lack of rainforest climate in central Africa, where precipitation is too low during the dry season.

Almost independent of model resolution the model realistically captures most aspects of the local and remote precipitation response to El Niño-Southern Oscillation (ENSO) events although the simulated amplitude is somewhat on the high side. However, the model fails to reproduce the observed precipitation response to ENSO variability in the Indian Ocean and Africa. This might be related to missing coupled air-sea feedbacks in an AGCM forced with observed sea surface temperatures.

An obvious deficiency of ECHAM5 is the overestimation of precipitation over the oceans, especially in the high-resolution simulations. This is a general problem in current GCMs, which could possibly be related to insufficient atmospheric absorption of solar radiation by aerosols, water vapor, or clouds. In particular, anomalous cloud absorption is still a matter of scientific debate (Valero et al. 2004; Li et al. 2004).

Acknowledgments. The authors thank colleagues at MPI who contributed to model development and performed the simulations, in particular, Monika Esch, Marco Giorgetta, Luis Kornblueh, and Uwe Schulzweida. The simulations were done on the NEC SX-6 at the German Climate Computing Center (DKRZ) in Hamburg, Germany.

\section{REFERENCES}

Adler, R. F., C. Kidd, G. Petty, M. Morissey, and H. M. Goodman, 2001: Intercomparison of global precipitation products: The third Precipitation Intercomparison Project (PIP-3). Bull. Amer. Meteor. Soc., 82, 1377-1396.

Arpe, K., L. Dümenil, and M. A. Giorgetta, 1998: Variability of the Indian monsoon in the ECHAM3 model: Sensitivity to sea surface temperature, soil moisture, and the stratospheric QBO. J. Climate, 11, 1837-1858.

Baumgartner, A., and E. Reichel, 1975: The World Water Balance. Elsevier, 179 pp.

Dümenil Gates, L., S. Hagemann, and C. Golz, 2000: Observed 
historical discharge data from major rivers for climate model validation. Rep. 307, Max Planck Institute for Meteorology, 93 pp. [Available from MPI for Meteorology, Bundesstr. 53, 20146 Hamburg, Germany.]

Fouquart, Y., and B. Bonnel, 1980: Computations of solar heating of the Earth's atmosphere: A new parameterization. Beitr. Phys. Atmos., 53, 35-62.

Gates, W. L., and Coauthors, 1999: An overview of the results of the Atmospheric Model Intercomparison Project (AMIP I). Bull. Amer. Meteor. Soc., 80, 29-55.

Hack, J. J., J. T. Kiehl, and J. W. Hurrell, 1998: The hydrologic and thermodynamic characteristics of the NCAR CCM3. $J$. Climate, 11, 1179-1206.

Hagemann, S., 2002a: An improved land surface parameter dataset for global and regional climate models. Rep. 336, Max Planck Institute for Meteorology, 21 pp. [Available from MPI for Meteorology, Bundesstr. 53, 20146 Hamburg, Germany.]

— 2002b: Validierung des Niederschlags in globalen Klimamodellen. Workshop zur hydrologischen ModellierungMöglichkeiten und Grenzen für den Einsatz hydrologischer Modelle in Politik, Wirtschaft und Klimafolgenforschung, K. Stephan, H. Bormann, and B. Diekkrüger, Eds., Kassel University Press, $115-127$.

Huffman, G. J., and Coauthors, 1997: The Global Precipitation Climatology Project (GPCP) combined precipitation dataset. Bull. Amer. Meteor. Soc., 78, 5-20.

Inness, P. M., J. M. Slingo, S. J. Woolnough, R. B. Neale, and V. D. Pope, 2001: Organising of tropical convection in a GCM with varying vertical resolution: Implications for the simulation of the Madden-Julian Oscillation. Climate Dyn., 17, 777-793.

Kalnay, E., and Coauthors, 1996: The NCEP/NCAR 40-Year Reanalysis Project. Bull. Amer. Meteor. Soc., 77, 437-471.

Köppen, W., 1923: Die Klimate der Erde.: Grundriss der Klimakunde., de Gruyter, 369 pp.

Krishna Kumar, K., B. Rajagopalan, and M. A. Cane, 1999: On the weakening relationship between the Indian monsoon and ENSO. Science, 284, 2156-2159.

Li, Z., W. Wiscombe, G. L. Stephens, and T. P. Ackerman, 2004: Disagreements over cloud absorption. Science, 305, 1240.

Lin, S. J., and R. B. Rood, 1996: Multidimensional flux-form semiLagrangian transport. Mon. Wea. Rev., 124, 2046-2068.

Lohmann, U., and E. Roeckner, 1996: Design and performance of a new cloud microphysics parameterization developed for the ECHAM4 general circulation model. Climate Dyn., 12, 557572.

Mlawer, E. J., S. J. Taubman, P. D. Brown, M. J. Iacono, and S. A. Clough, 1997: Radiative transfer for inhomogeneous atmospheres: RRTM, a validated k-correlated model for the longwave. J. Geophys. Res., 102, 16 663-16 682.

New, M., M. Hulme, and P. D. Jones, 2000: Representing twentieth-century space-time climate variability. Part II: Development of 1901-96 monthly grids of terrestrial surface climate. J. Climate, 13, 2217-2238.

Nordeng, T. E., 1994: Extended versions of the convective parameterization scheme at ECMWF and their impact on the mean and transient activity of the model in the tropics. Tech. Memo. 206, European Centre for Medium-Range Weather Forecasts, Reading, United Kingdom, 25 pp.
Pope, V. D., and R. A. Stratton, 2002: The processes governing horizontal resolution sensitivity in a climate model. Climate Dyn., 19, 211-236.

Randel, D. L., T. H. Vonder Haar, M. A. Ringerud, G. L. Stephens, T. J. Greenwald, and C. L. Combs, 1996: A new global water vapor dataset. Bull. Amer. Meteor. Soc., 77, 1233-1246.

Roeckner, E., and Coauthors, 1996: The atmospheric general circulation model ECHAM-4: Model description and simulation of present-day climate. Rep. 218, Max Planck Institute for Meteorology, $90 \mathrm{pp}$. [Available from MPI for Meteorology, Bundesstr. 53, 20146 Hamburg, Germany.]

—, and Coauthors, 2003: The atmospheric general circulation model ECHAM5. Part I: Model description. Rep. 349, Max Planck Institute for Meteorology, $127 \mathrm{pp}$. [Available from MPI for Meteorology, Bundesstr. 53, 20146 Hamburg, Germany.]

— , and Coauthors, 2006: Sensitivity of simulated climate to horizontal and vertical resolution in the ECHAM5 atmosphere model. J. Climate, 19, 3771-3791

Roesch, A., and E. Roeckner, 2006: Assessment of snow cover and surface albedo in the ECHAM5 general circulation model. J. Climate, 19, 3828-3843.

Ropelewski, C. F., and M. S. Halpert, 1987: Global and regional scale precipitation patterns associated with the El Niño/ Southern Oscillation. Mon. Wea. Rev., 115, 1606-1626.

Rudolf, B., and F. Rubel, 2005: Global precipitation. Observed Global Climate, M. Hantel, Ed., Landolt-Boernstein: Numerical Data and Functional Relationships, Vol. 6, SpringerVerlag.

Sperber, K. R., and T. N. Palmer, 1996: Interannual tropical rainfall variability in general circulation model simulations associated with the Atmospheric Model Intercomparison Project. J. Climate, 9, 2727-2750.

Tiedtke, M., 1989: A comprehensive mass flux scheme for cumulus parameterization in large-scale models. Mon. Wea. Rev., 117, 1779-1800.

Tompkins, A. M., 2002: A prognostic parameterization for the subgrid-scale variability of water vapor and clouds in largescale models and its use to diagnose cloud cover. J. Atmos. Sci., 59, 1917-1942.

Uppala, S. M., and Coauthors, 2005: The ERA-40 re-analysis. Quart. J. Roy. Meteor. Soc., 131, 2961-3012.

Valero, F. P. J., R. D. Cess, and S. K. Pope, 2004: Disagreements over cloud absorption. Science, 305, 1239.

Webster, P., and S. Yang, 1992: Monsoon and ENSO: Selectively interactive systems. Quart. J. Roy. Meteor. Soc., 118, 877-926.

Wild, M., A. Ohmura, H. Gilgen, E. Roeckner, M. Giorgetta, and J.-J. Morcrette, 1998: The disposition of radiative energy in the global climate system: GCM-calculated versus observational estimates. Climate Dyn., 14, 853-869.

Wu, R., and B. P. Kirtman, 2004: Impacts of the Indian Ocean on the Indian summer monsoon-ENSO relationship. J. Climate, 17, 3037-3054.

Xie, P., and P. Arkin, 1997: Global precipitation: A 17-year monthly analysis based on gauge observations, satellite estimates, and numerical model outputs. Bull. Amer. Meteor. Soc., 78, 2539-2558. 